Research Article

\title{
Experimental Studies of Single-Layer Reticulated Domes with Isolated Supports
}

\author{
Guibo Nie $\mathbb{D}^{1}$ and Kun Liu $\mathbb{D}^{2,3}$ \\ ${ }^{1}$ Key Laboratory of Earthquake Engineering and Engineering Vibration, Institute of Engineering Mechanics, \\ China Earthquake Administration, Harbin 150000, China \\ ${ }^{2}$ Key Lab of Structures Dynamic Behavior and Control of the Ministry of Education, Harbin Institute of Technology, \\ Harbin 150090, China \\ ${ }^{3}$ Key Lab of Smart Prevention and Mitigation of Civil Engineering Disasters of the Ministry of Industry and Information \\ Technology, Harbin Institute of Technology, Harbin 150090, China
}

Correspondence should be addressed to Guibo Nie; nieguibo0323@163.com

Received 27 February 2018; Revised 27 July 2018; Accepted 9 September 2018; Published 1 October 2018

Academic Editor: Brij N. Agrawal

Copyright (c) 2018 Guibo Nie and Kun Liu. This is an open access article distributed under the Creative Commons Attribution License, which permits unrestricted use, distribution, and reproduction in any medium, provided the original work is properly cited.

\begin{abstract}
To study the seismic behavior of a single-layer reticulated dome subjected to severe earthquakes, a series of shaking table tests were conducted for this paper. Seismic responses including the acceleration, displacement, and strains gathered at the members and nodes were discussed. The dynamic characteristics, including structure frequencies and damping ratio, were obtained through the results under the input excitation of white noise and the fast sine sweeping with different amplitudes. Various isolation devices usually installed in the upper portion of the structures have been widely used to reduce the dynamic responses for more than three decades. However, these isolation devices deal mostly with either horizontal isolation or vertical isolation, which is not applicable for synchronous isolation in both horizontal and vertical isolation. Therefore, an innovative isolated support for threedimensional isolation was invented. In order to understand the earthquake-isolation effects of a single-layer reticulated dome with the isolated support, a series of shaking table tests were conducted. The dynamic behavior of the structure was then investigated and discussed using the acceleration and displacement responses of the tested structures with or without the isolated supports. The experimental results show that the isolated support invented in this study had a remarkable earthquake-isolation action in both horizontal and vertical isolation.
\end{abstract}

\section{Introduction}

Steel space structures have been widely used all over the world, even in countries vulnerable to the threat of earthquakes, such as the Japan, the United States and China. Largespan space structures involve a large span in two horizontal directions covering a wide area with few or no vertical supports inside the structure. These include structures such as sports gymnasia, exhibition halls, and other large-scale public buildings, which have developed rapidly in China in the past three decades. China spans the circum-Pacific seismic zone and the Eurasian seismic zone with frequent strong earthquakes. However, the mechanical characteristics, including elastic and inelastic behavior, of large-span space structures, for which seismic resistant design is very important, are still not thoroughly understood. In the 2013 M7.0 Lushan earthquake in the Sichuan province of China, two typical large-span space structures were found by Zhang et al. [1] to be in a severe state of damage. One of them was dismantled, and the other was repaired at extensive costs after the earthquake. The numerical simulation was conducted to reveal the damage mechanism of the Lushan high school gymnasium, which shows that the supports of the dome have severe damage consistent with the damage investigation. So, the support of the large-span space structure should be further studied to resist the earthquake.

Experimental tests are not only used for providing a database for the validation of the numerical structures but 
also for playing a key role in the development of the design rules for criteria. Large amounts of experimental tests have been conducted to study the seismic behavior of steel structures during the past two decades. Nader and AstanehAsl [2] found that a well-proportioned semirigid connection can effectively participate in the nonlinear behavior of the structure based on the shaking table test. Lignos et al. [3] carried out the collapse assessment of steel frame structures through the comparison of results between experimental data obtained from a shaking table collapse test and the corresponding numerical analysis, and it validates that the accurate simulation of steel component deterioration is important for collapse behavior prediction. Vasdravellis et al. [4] investigated the behavior of the composite beams through a shaking table test and found that the response of the beam varied significantly with different degrees of partial interaction between slab and beam. At the same time, some researchers have focused on the validation of the numerical structures or proposed methods. Barroso and Rodriguez [5] evaluated a proposed damage detection index for a benchmark structure, and Zhou and $\mathrm{Li}$ [6] verified a prediction method based on shaking table test data. Some shaking table tests have been conducted to compare the numerical results with experimental results [7-9], and a series of shaking table tests on steel moment-frame structures have also been conducted to validate structural modelling techniques and propose design procedures [10-12] including a full-scale steel building test [10]. Different numerical analysis methods were adopted in these studies because it is hard to find out a uniform numerical analysis method to simulate all the cases, which reveals that the numerical simulation study cannot replace the experimental study totally.

Many steel structures are found in a damaged or collapsed state after a severe earthquake. The application of seismic mitigation and isolation techniques is the most practical and reliable method to reduce the structural responses subjected to earthquake loading. Lin et al. [13, 14] conducted a shaking table test on a full-scale steel frame structure with a smart active control system, and then the performance and robustness of the proposed control system was evaluated, which demonstrated that the performance of the proposed control system was over the traditional active control. Sun et al. [15] designed two new-type BRBs and then verified through shaking table tests the superiority of the full-scale structure with designed BRB under extremely severe earthquakes. In order to compare the effects of shape memory alloy (SMA) wire cable on the dynamic responses of the steel frame structure under seismic load, three kinds of whole control schemes were conducted by Yan et al. [16] in the shaking table test. The results showed that the SMA damper could change the dynamic characteristics of the structure and reduce the dynamic response of structure under seismic motions. To date, the most widely used isolation devices are various types of dampers. Monir and Zeynali [17] tested a developed friction damper installed inside a SDOF steel frame through a shaking table under several earthquake excitations, and it proved that the proposed friction damper reduced the lateral displacements and the base shears of the multistory building. Hwang et al. [18] conducted a shaking table test for a three-story steel structure to investigate the seismic responses of the structure with or without linear viscous dampers, and the test results showed that the toggle-brace system constructed by linear viscous dampers enhanced the seismic response control on a stiff structure. Chang et al. [19] also conducted a shaking table test on a scale structure with viscoelastic dampers to investigate the structural seismic behavior using this type of damper, and the similar conclusions were obtained. Wongprasert and Symans [20] conducted a shaking table test on a scale steel frame with variable-orifice fluid dampers and demonstrated that this kind of structure significantly reduced the response of the superstructure. From all of the above literature about shaking table tests on steel structures, it can be seen that much work has been done on the seismic behavior and isolation technique of the structure. However, studies have mainly focused on the steel frame, and little attention was paid to large-span space structures.

Based on the above discussions, it can conclude that the seismic mitigation and isolation techniques of the large-span space structure should be studied and the experimental study by shaking table is a good methodology. In this paper, a shaking table test was conducted on a single-layer reticulated dome, which is a typical large-span space structure [21], to investigate the seismic behavior of the structure. An innovative isolated support for three-dimensional isolation was then invented. In addition, a series of shaking table tests on single-layer reticulated domes were conducted to validate the effectiveness of the support. Experimental results show that the dynamic behavior of the structure with or without the isolated supports is clearly different, and the isolated support invented in this paper has a remarkable earthquakeisolation action in both horizontal and vertical isolation.

\section{Outline of the Experiment}

2.1. Details of the Test Structure. The test structure was a single-layer reticulated dome with a span of $2.7 \mathrm{~m}$ and a height of $0.9 \mathrm{~m}$. Two tests with the same models with and without isolated supports were conducted using the shaking table, as shown in Table 1. Usually when the model test is carried out, the structure model should be designed according to the similarity theory. The geometric size, the material property index, the load size and the dynamic performance of the model should meet the similar requirements. Only in this way can the model test be derived from the similar conditions to derive the reaction of the prototype structure. However, it is difficult to achieve a complete similarity between the model structure and the prototype structure. Therefore, this paper neglected some minor factors in the design and manufacture of the model. For example, the section size and mass density of the bar are difficult to satisfy the similar conditions, which are replaced according to the models that can be purchased in the steel market. In addition, in the process of model design, the conditions of test and processing technology should be considered comprehensively. Taking into account the prototype size and the size of shaking table and the limitations of the relevant experimental equipment, the model span is 
TABle 1: Details of the test structures.

\begin{tabular}{lcc}
\hline Number & $\begin{array}{c}\text { The input } \\
\text { excitation }\end{array}$ & The support \\
\hline Structure B1 & $\begin{array}{c}\text { Three-dimensional } \\
\text { excitations }\end{array}$ & Without isolation \\
Structure B2 & $\begin{array}{c}\text { Three-dimensional } \\
\text { excitations }\end{array}$ & $\begin{array}{c}\text { With isolated } \\
\text { supports }\end{array}$ \\
\hline
\end{tabular}

determined to be $2.7 \mathrm{~m}$ and the span of the prototype structure is $40 \mathrm{~m}$, so the length similarity ratio is $2.7 / 40=0.068$. The stress similarity ratio with value of 1 is used because of the same material as the prototype. In order to truly reflect the influence of gravity load, the acceleration similarity ratio with value of 1 is used.

There were seven kinds of members in structure $\mathrm{B} 1$ and structure B2, as shown in Figure 1(a) and Table 2. Structure B1 corresponding to the normal support without isolation technology and structure B2 with the isolated support installed are shown in Table 1, Figures 1(a) and 1(b). A solid ball made of steel with a diameter of $250 \mathrm{~mm}$ was designed to represent the deadweight of elements and roof loads, and the test structures with or without isolation supports are shown in Figures 1(c) and 1(d). The pipes with sections of $160 \times 160 \times 8$ formed the steel beams which were welded to locating plates, and then the locating plates were connected with shaking table via high-strength friction grip bolts. The four isolated supports are located at the lower side of the steel beam as the red solid circle shown in Figure 1(b), and the supporting roof and the steel beam are welded together. The outer nodes used hollow hemi steel balls with diameters of $120 \mathrm{~mm}$, denoted as $\mathrm{A}$ in the Figures 1(a) and 1(b), and the other nodes used solid steel balls with diameters of $250 \mathrm{~mm}$, denoted as B in the Figures 1(a) and 1(b). The temporary strut was connected with the steel beam and solid ball via threads to complete the bearing and provide accurate vertical location of the solid ball. The geometric position of the structure was measured several times by an electronic total station after removal of the temporary strut. The maximum deviation of the node was $11.8 \mathrm{~mm}$, which was about $1 / 230$ of the span of structure, and the mean deviation of the node was $6.9 \mathrm{~mm}$, which was about $1 / 390$ of the span of the structure and which indicated the structure had a high processing accuracy.

2.2. The Arrangement of Measuring Points. In this paper, the arrangement of measuring points of structure B2 is identical to structure $\mathrm{B} 1$, which will be described in the following part. Nine groups of measuring points used for strain gages were placed on the structure, with most of them concentrated at the quarter of the structure and two groups of validated measuring points located at the other part. Each measuring point included four strain gages symmetrically arrayed along the radial direction of the member. The measuring points of S1 and S2 were located at the end of the member, and the other measuring points were located at the middle of the member, as shown in Figures 2(a) and 3(a). Eight groups of measuring points with each including three-dimensional acceleration sensors were selected to get the dynamic response of acceleration, as shown in Figures 2(b) and 3(b). The measuring points of $\mathrm{A} 1$ and A2 were arranged symmetrically on the shaking table to measure the acceleration of the shaking table in three directions. The measuring point of A8 was used as a checking point with A2. The acceleration of the structure in three directions was measured by the acceleration sensor at the measuring points of A3, A4, and A5. The acceleration of the steel beam was measured by the acceleration sensor at the measuring points of A6 and A7. Four groups of measuring points with each including threedimensional displacement sensors were selected to get the dynamic response of displacement, as shown in Figures 2(b) and $3(\mathrm{~b})$. The measuring points of D1 and D2 were used to obtain the displacement of the shaking table and the steel beam. The displacements of the structure in three directions were measured by the displacement sensors at the measuring points of D3 and D4.

2.3. Material Test on the Members of the Structure. The solid steel balls in this test were cast with Q235B steel, and the other balls were hollow hemi welded balls and the elements were seamless steel pipes. At the same time, to accurately simulate the responses under seismic motion and to provide effective material property data, 8 groups of members were tested using a universal testing machine to get stress-strain curves. The mean value of yield strength was $268 \mathrm{MPa}$, and the mean Young's modulus was $166 \mathrm{GPa}$. The mean external diameter was determined to be $8.05 \mathrm{~mm}$, and the mean thickness was determined to be $1.094 \mathrm{~mm}$ by measuring 80 members, as shown in Table 3.

\section{The Three-Dimensional Isolated Support}

3.1. The Working Principle of the Isolated Support. To date, vertical isolation is arduous to implement in infrastructure facilities due to several reasons, such as the extremely high demand of vertical bearing capacity of the isolated supports and the exceedingly high need of vertical deformation of the isolated support. However, the isolated device is usually made of material with low deformability, which leads to overwhelmingly large vertical stiffness. This study designed a three-dimensional mechanical isolation device to provide interlayer seismic isolation for the single-layer reticulated dome with a light roof. The device is installed at the top of the column and requires less vertical bearing capacity compared with traditional base isolation. However, the device requires much larger deformation due to the amplification effect of the lower supporting structure.

In order to design a practical and refined threedimensional mechanical isolation device, the vertical isolation and horizontal isolation were separated and worked independently. The isolated support mainly consists of a spring system that includes a horizontal and vertical spring system, as shown in Figure 4(a). The horizontal spring was installed between the end plate fixed at the bottom plate and a sliding device slipped along the steel rod, as shown in Figures 4(a) and 4(b). The vertical spring was installed between the top plate and the sliding device via hinge 


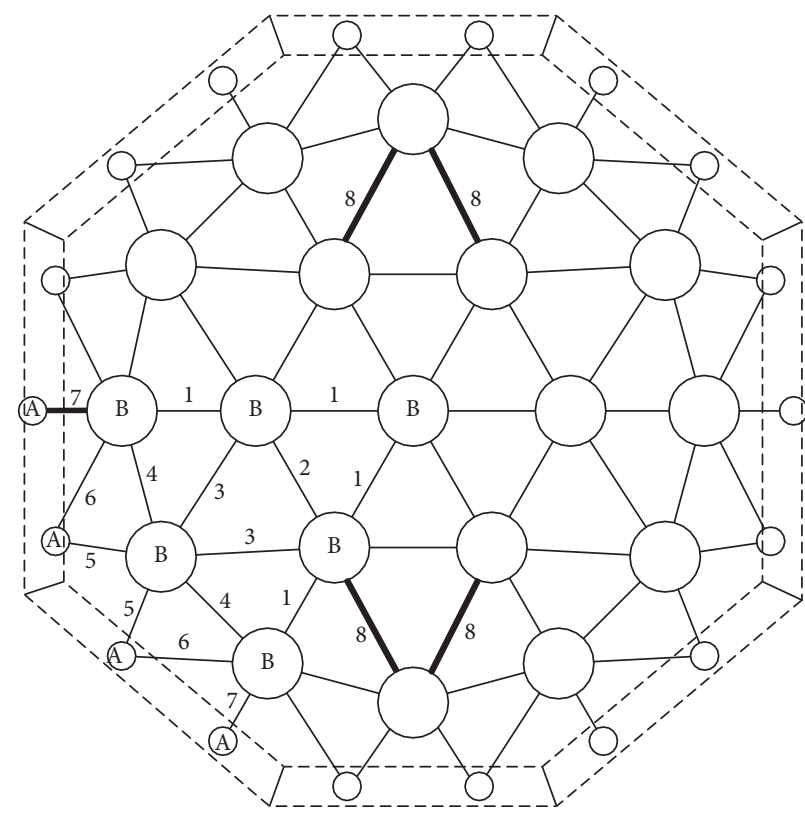

(a)

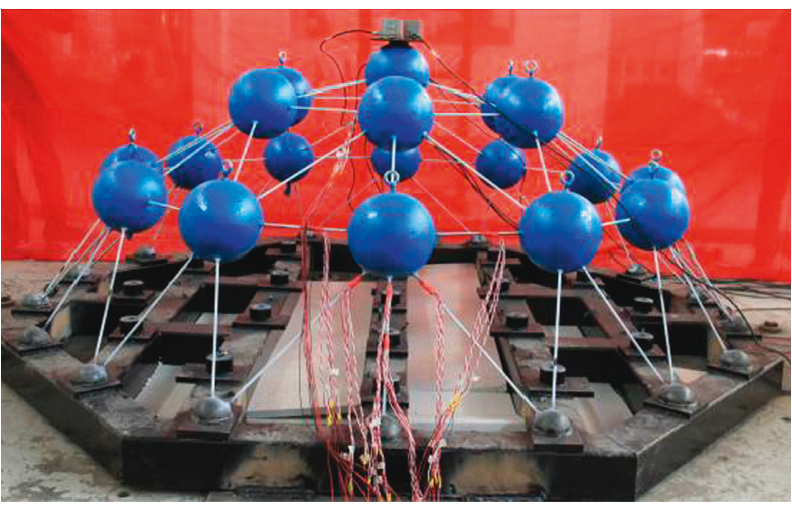

(c)

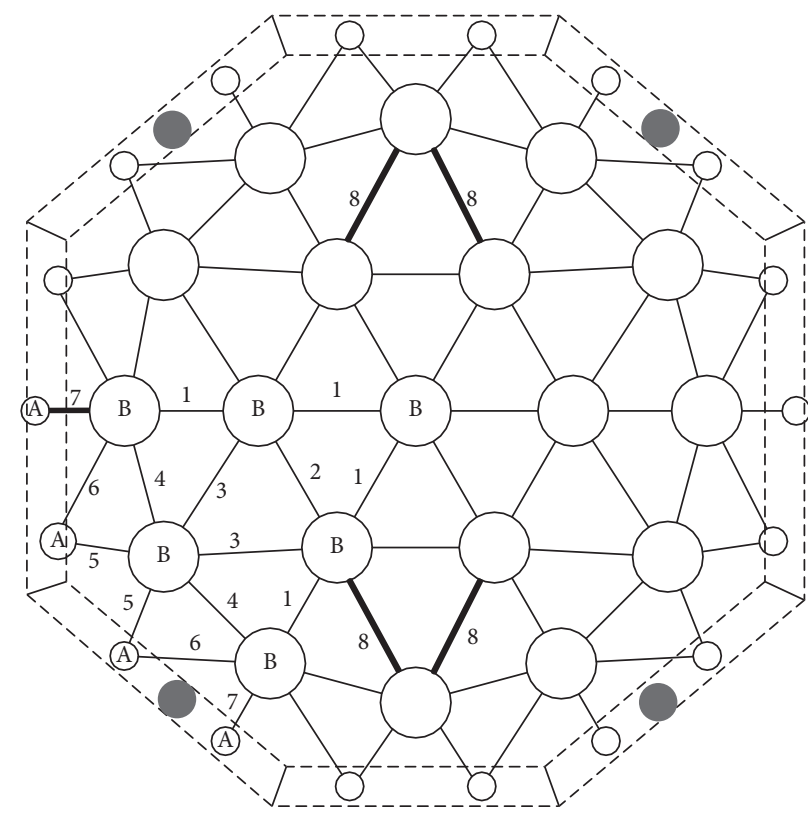

(b)

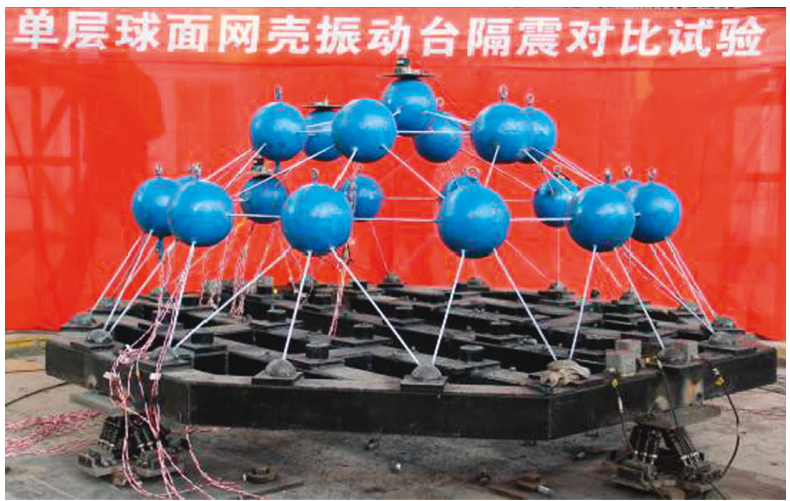

(d)

Figure 1: Details of the test structure. (a) The members and nodes of structure B1; (b) the members and nodes of structure B2; (c) structure B1 without isolation; (d) structure B2 with isolated supports.

TABle 2: Details of the circular pipe used in the test structure.

\begin{tabular}{lcccc}
\hline $\begin{array}{l}\text { Number of } \\
\text { the members }\end{array}$ & $\begin{array}{c}\text { Cross } \\
\text { section }(\mathrm{mm})\end{array}$ & $\begin{array}{c}\text { Length } \\
(\mathrm{mm})\end{array}$ & $\begin{array}{c}\text { Number of } \\
\text { the members }\end{array}$ & $\begin{array}{c}\text { Cross } \\
\text { section }(\mathrm{mm})\end{array}$ \\
\hline 1 & $8 \times 1$ & 320 & 5 & $8 \times 1$ \\
2 & $8 \times 1$ & 309 & 6 & $8 \times 1$ \\
3 & $8 \times 1$ & 443 & 7 & $8 \times 1$ \\
4 & $8 \times 1$ & 285 & 8 & $6 \times 1$ \\
\hline
\end{tabular}

devices, as shown in Figure 4(c). The horizontal spring that was symmetrically configured along the bottom presented a compression state under the vertical force caused by the weight of the structure. Then, the horizontal spring presented either compression or tension under vertical seismic motion. Furthermore, the horizontal spring at one side of the two horizontal directions presented a compression state under horizontal seismic motion. Moreover, the horizontal spring was installed between the steel box and sliding device, which could allow a much larger deformed space and provide an installment place for an additional spring if the stiffness of the horizontal spring cannot reach the design requirements. The vertical spring mainly consisted of a spring support sleeve in the form of a diagonal brace that could eliminate the effect of P- $\Delta$. The vertical spring presented a compression state under vertical compressive force and the spring support sleeve then presented a tension state through an adjustable rod used as a stop block. Therefore, the above design indicated that the vertical isolation system considerably reduced the seismic effect under vertical compressive force and was also beneficial, but with a moderate impact, under vertical tension force when considering 


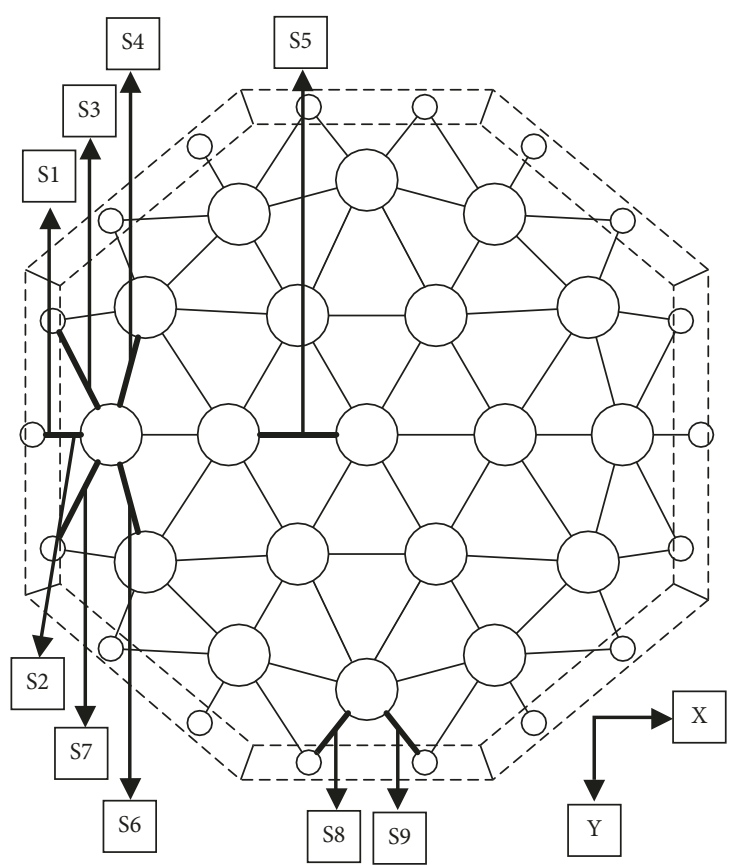

(a)

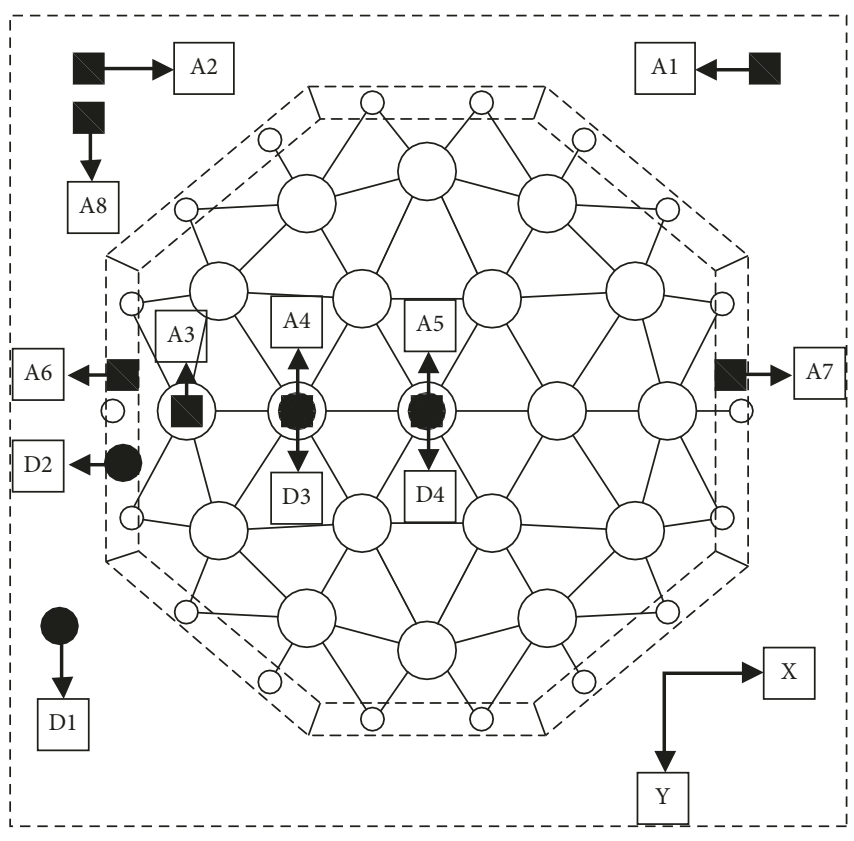

(b)

FIGURE 2: Arrangement of measuring points. (a) Arrangement of strain gages; (b) arrangement of the accelerometers and displacement sensors.

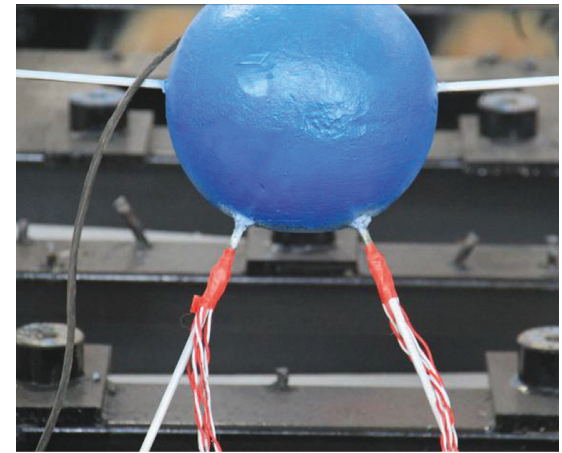

(a)

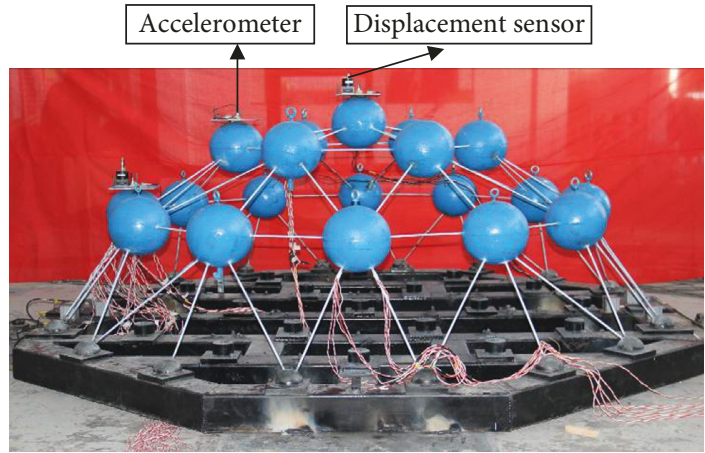

(b)

FIGURE 3: Details of the measuring points. (a) Measuring point of strain gages; (b) measuring points of accelerometer and displacement sensor.

TABle 3: Results of the material test.

\begin{tabular}{lcccc}
\hline $\begin{array}{l}\text { Steel } \\
\text { type }\end{array}$ & $\begin{array}{c}\text { Yield } \\
\text { strength }\end{array}$ & $\begin{array}{c}\text { Young's } \\
\text { modulus }\end{array}$ & $\begin{array}{c}\text { External } \\
\text { diameter }(\mathrm{mm})\end{array}$ & $\begin{array}{c}\text { Thickness } \\
(\mathrm{mm})\end{array}$ \\
\hline Q235B & $268 \mathrm{MPa}$ & $166 \mathrm{GPa}$ & 8.05 & 1.094 \\
\hline
\end{tabular}

the action of structural gravity. In addition, the overturning moment was relatively small due to the smaller height of the center of gravity at the interlayer seismic isolation and the ring beam welded with the upper single-layer reticulated dome. The isolated support adopted modular assembly to obtain a higher installment accuracy and convenient repair. Moreover, the spring in this support can be replaced by a disc spring, which provides much larger bearing capacity in practical engineering applications.

3.2. Calculation of Spring Stiffness. The parameters of the spring, such as its stiffness and limit deformation capacity, are key issues in designing an isolated support including a horizontal and vertical spring system after an in-depth understanding of the isolation mechanism. Not only the isolation effect but also the vertical bearing capacity should be considered when selecting the parameters of the vertical spring. Spring stiffness should not be too low when considering the creep effect of the spring under the permanent load and the need for vertical bearing capacity. It is widely 


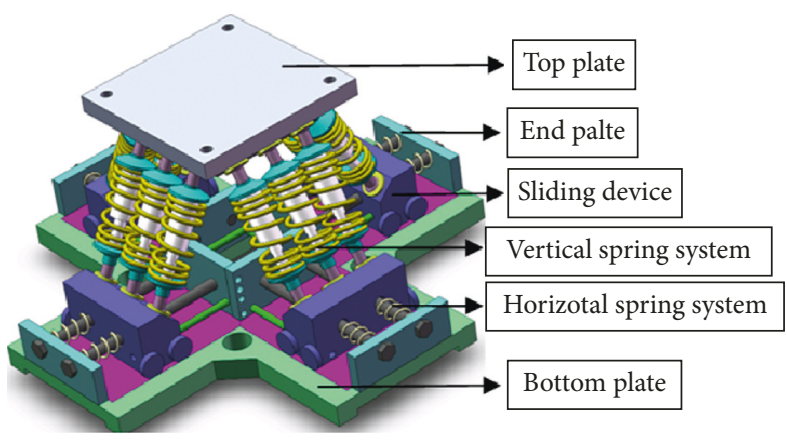

(a)

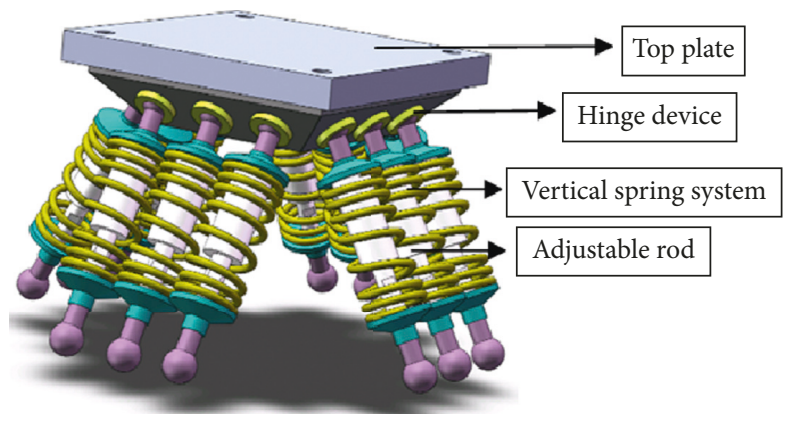

(c)

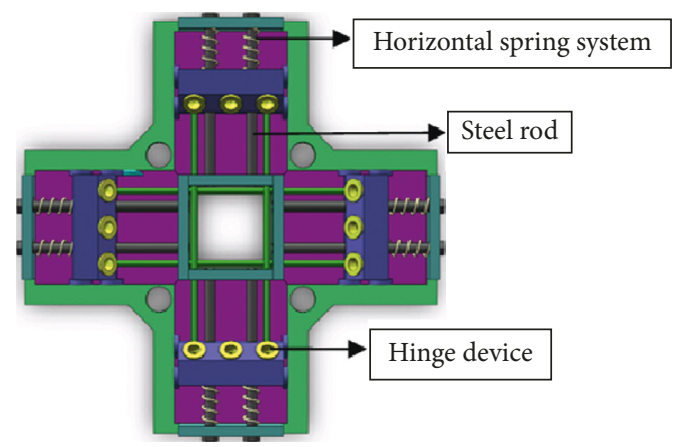

(b)

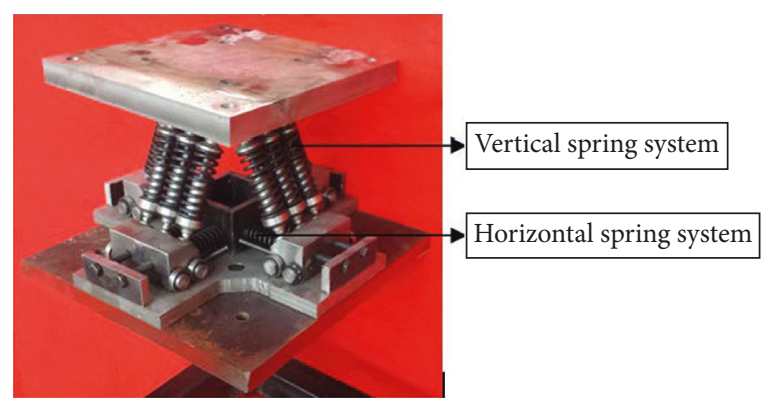

(d)

FIGURE 4: Details of the three-dimensional mechanical isolation device. (a) Isometric drawing of the support; (b) top view of horizontal isolation; (c) isometric drawing of vertical isolation; (d) the support used in the test.

shared that the deformation capacity should be increased when the safety of vertical bearing capacity of the isolated support under rarely occurring earthquake can be reached. Both of the isolation effect and deformed capacity under rarely occurring earthquake should be considered when selecting the stiffness of the horizontal spring. The vertical spring stiffness can be defined by Formula (1), where the total mass of the roof structure of the tested structure is $2000 \mathrm{~kg}$ and the working angle of the vertical spring is 60 degrees.

$$
G=4 \times 12 \times K_{\mathrm{v}} \times \sin 60^{\circ} \times \Delta_{\mathrm{v}},
$$

where $G=$ representative value of gravity load of the tested structure; $K_{\mathrm{v}}=$ the stiffness of a single vertical spring; and $\Delta_{\mathrm{V}}=$ the spring deformation. The limit vertical deformation is defined as $60 \mathrm{~mm}$, and the allowed deformation is $10 \mathrm{~mm}$ under normal use. $K_{\mathrm{v}}$ can then be obtained with the value of $24.05 \mathrm{~N} / \mathrm{mm}$. Furthermore, a spring with a spring wire diameter of $4.5 \mathrm{~mm}$, diameter of the spring of $35 \mathrm{~mm}$, length of $100 \mathrm{~mm}$, and stiffness of $25.9 \mathrm{~N} / \mathrm{mm}$ was adopted. The limit deformation of the horizontal is $40 \mathrm{~mm}$ at the acceleration of $0.5 \mathrm{~g}$ when installed the isolated support, as shown in the following equation:

$$
0.5 \times G=4 \times 2 \times K_{\mathrm{h}} \times \Delta_{\mathrm{h}},
$$

where $G=$ the representative value of the gravity load of the tested structure; $K_{\mathrm{h}}=$ the stiffness of a horizontal single spring; and $\Delta_{\mathrm{h}}=$ the spring deformation. $K_{\mathrm{h}}$ can then be obtained with the value of $31.26 \mathrm{~N} / \mathrm{mm}$. Furthermore, the spring with a $4 \mathrm{~mm}$ spring wire diameter, $25 \mathrm{~mm}$ spring diameter, spring length of $60 \mathrm{~mm}$, and spring stiffness of $25.2 \mathrm{~N} / \mathrm{mm}$ was adopted.

\section{Test Scheme and Dynamic Characteristics of the Test Structure}

4.1. The Test Scheme. Two structures, each with the same kinds of members, were designed for this paper, as shown in Tables 1 and 2. Each structure was subjected to the following sequence of tests. First, the input excitation such as white noise and fast sine frequency sweep was conducted to obtain the dynamic characteristics of the structure such as frequency and damping ratio. A series of seismic motions were then selected to investigate the seismic performance of the structure with or without the isolated supports. Finally, the structures were subjected to Taft seismic motion (1952) to investigate the plastic and collapse behavior. Three different acceleration records from the historical seismic motions were selected to investigate the elastic, plastic, and collapse behavior of the structures through the shaking table test. The Taft earthquake (1952), the 311 Japan earthquake (2011), and Lsfx China earthquake (2013) were used in this paper. Each of the earthquake motions was increased in peak value from $35 \mathrm{~cm} / \mathrm{s}^{2}$ to $1500 \mathrm{~cm} / \mathrm{s}^{2}$. The time scale of the input acceleration excitation used in the test was an original record, which was compressed to $1 / 3$ of its duration so that the earthquake response spectrum would have a peak value with a frequency similar to that of the structure. The structures B1 and B2 were tested to investigate the behavior with or without the isolated supports, as shown in Table 4. The 311 earthquake then 
TABLE 4: Details of the test schemes structure B1 and B2.

\begin{tabular}{lccc}
\hline $\begin{array}{l}\text { Name of input } \\
\text { excitation }\end{array}$ & $\begin{array}{c}\text { Peak value } \\
\left(\mathrm{cm} / \mathrm{s}^{2}\right)\end{array}$ & $\begin{array}{c}\text { Name of input } \\
\text { excitation }\end{array}$ & $\begin{array}{c}\text { Peak value } \\
\left(\mathrm{cm} / \mathrm{s}^{2}\right)\end{array}$ \\
\hline Taft seismic motion $(1952)$ & $35 ; 100 ; 200 ; 400 ; 620 ; 700$ & 311 seismic motion $(2011)$ & $35 ; 100 ; 200 ; 400$ \\
Lsfx seismic motion (2013) & $35 ; 100 ; 200 ; 400$ & White noise & 50 \\
\hline
\end{tabular}

occurred in Japan in the same year, and the Lushan earthquake occurred at China in 2013. Two typical large-span space structures were found in a state of severe damage after the Lushan earthquake. Therefore, these two more recent seismic motions were included in the structures B1 and B2.

4.2. Dynamic Characteristics of the Test Structure. Three input excitations, including white noise, fast sine frequency sweep, and hammering method were usually used to obtain the dynamic characteristic of structure such as frequency and damping ratio. Based on the previous study [22], the difference of the results of these three methods was within $3 \%$ after eliminating all kinds of noise interference, such as electromagnetic interference, vibration of the moving simulator of the table (MST), and vibration of the actuator under the shaking table. Therefore, only white noise was used in this study. The corresponding values of structure B1 and structure B2 were shown in Tables 5 and 6 .

\section{Details of the Shaking Table Test with or without the Three-Dimensional Isolated Support}

5.1. Details of the Input Excitation. Vertical ground motions are significantly less affected than horizontal seismic ground motions in buildings such as wooden structures, masonry structures, and reinforced concrete structures, and only horizontal seismic motions are considered in seismic designs under normal circumstances. However, large-span space structures, especially single-layer reticulated domes, are sensitive to deformation, which indicated that the vertical seismic ground motion is as important as horizontal seismic ground motions. Furthermore, the frequency range of largespan space structures is much larger than other structures, which means the spatial structure may amplify some dynamic responses to both vertical vibrations and horizontal vibrations. Therefore, the structure B1 and B2 with or without the isolated supports were conducted by shaking table test under three-dimensional input of seismic ground motions. In order to investigate the dynamic performance of the structure subjected to different seismic motions and duration times, three seismic motions, Taft motion (1954), 311 motion (2011), and Lsfx motion (2013) were selected in this paper, as shown in Figures 5-7. The Taft and Lsfx seismic motions represent a short wave period, and 311 seismic motion represents a long wave period. The three seismic ground motions have comparable spectral acceleration values, as can be seen in Table 7 . The frequencies corresponding to the maximum amplitude in the $x$ direction of the three seismic motion are $6.87 \mathrm{~Hz}$, $10.67 \mathrm{~Hz}$, and $20.03 \mathrm{~Hz}$. The frequencies corresponding to the maximum amplitude in the $y$ direction are $4.18 \mathrm{~Hz}, 11.08 \mathrm{~Hz}$, and $17.22 \mathrm{~Hz}$. However, the frequencies corresponding to the maximum amplitude in the $z$ direction have a much greater difference with the values of $13.15 \mathrm{~Hz}, 17.25 \mathrm{~Hz}$, and $28.12 \mathrm{~Hz}$. Therefore, the above three seismic motions are adequate in the duration time and frequency to investigate the dynamic behaviors of the structure. The component with the bigger peak value in the horizontal seismic motions was used as $y$ input excitation, and the other two components were used as $x$ and $z$ input excitations. Herein, the two horizontal input excitations of $x$ and $y$ as well as the vertical input excitation of $z$ were progressively increased simultaneously. The test structure was subjected to a sequence of $0.035 \mathrm{~g}$ (level 1), $0.1 \mathrm{~g}$ (level 2), $0.2 \mathrm{~g}$ (level 3), $0.4 \mathrm{~g}$ (level 4), $0.62 \mathrm{~g}$ (level 5), and $0.7 \mathrm{~g}$ (level 6) of the three seismic motions.

5.2. Seismic Performance of the Structure. The shaking table tests were conducted with the seismic ground motions shown in Table 6. This paper describes the dynamic behavior and results of structure B1 and structure B2 before and after the application of the isolated supports under Taft motion with an amplitude of $620 \mathrm{~cm} / \mathrm{s}^{2}$, as shown in Figures $8-11$. As can be seen from Figure 8, the acceleration responses were greatly reduced when the isolated supports were implemented to the test structure. Figures $8(\mathrm{~d})-8(\mathrm{f})$ present the Fourier amplitude with or without the isolated supports, which indicates that the frequencies were obviously changed after application of the isolated supports. The peak value of the acceleration time history curve of the top node in Figure 8(b) was $3201 \mathrm{~cm} / \mathrm{s}^{2}$ for the structural model without isolated support, which was 5.2 times the peak value of the input seismic motion. But the peak value of the acceleration time history curve of the top node in Figure $8(\mathrm{~b})$ was $342 \mathrm{~cm} / \mathrm{s}^{2}$ for the structural model with isolated support, which is much smaller than that for the structural model without isolated support. The design input acceleration of the large-span space structure was based on the seismic ground motion and did not consider the amplification effect of the upper structure in the Chinese design criteria, which may have led to the structure's lack of security. The maximum displacement responses were slightly smaller after using the isolated support since the supports were vibrational isolation devices, as can be seen in Figure 9. Moreover, the isolated efficiency of the stress responses were very positive, which was a key issue for designing this kind of structure. The material of the members in the structure without the isolated supports reached plastic at test when subjected to 311 seismic ground motion with an amplitude of $400 \mathrm{~cm} / \mathrm{s}^{2}$. In contrast, the corresponding results of the structure after using the isolated supports did not reach plastic development under all the test schemes, and no obvious plastic phenomena occurred in the structural model with isolated supports during the whole test. Two members of structure B1 displayed an obvious bending under Taft motion 
TABLE 5: Fourth stage of natural frequency and damping ratio of structure B1 before inputting seismic motion.

\begin{tabular}{lccccc}
\hline Number & $\begin{array}{c}\text { The frequency } \\
(\mathrm{Hz})\end{array}$ & $\begin{array}{c}\text { The damping } \\
\text { ratio }\end{array}$ & Number & $\begin{array}{c}\text { The frequency } \\
(\mathrm{Hz})\end{array}$ & $\begin{array}{c}\text { The damping } \\
\text { ratio }\end{array}$ \\
\hline 1 & 16.74 & 0.0131 & 3 & 19.65 & 0.0077 \\
2 & 18.11 & 0.0082 & 4 & 20.74 & 0.0053 \\
\hline
\end{tabular}

TABLE 6: Fourth stage of natural frequency and damping ratio of structure B2 before inputting seismic motion.

\begin{tabular}{lccccc}
\hline Number & $\begin{array}{c}\text { The frequency } \\
(\mathrm{Hz})\end{array}$ & $\begin{array}{c}\text { The damping } \\
\text { ratio }\end{array}$ & Number & $\begin{array}{c}\text { The frequency } \\
(\mathrm{Hz})\end{array}$ & $\begin{array}{c}\text { The damping } \\
\text { ratio }\end{array}$ \\
\hline 1 & 6.82 & 0.0191 & 3 & 8.33 & 0.0172 \\
2 & 7.84 & 0.0183 & 4 & 9.09 & 0.0154 \\
\hline
\end{tabular}

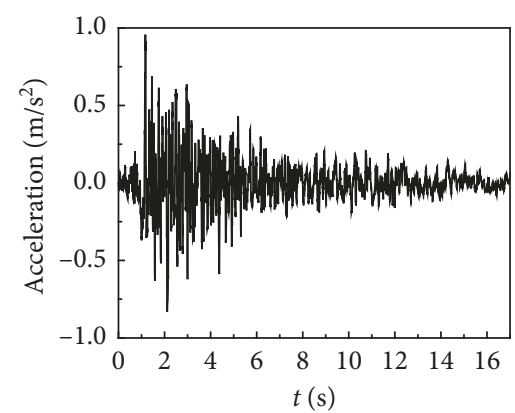

(a)

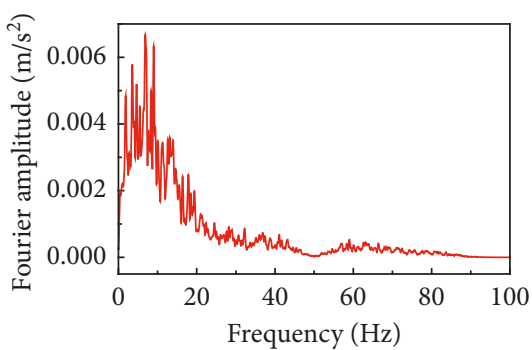

(d)

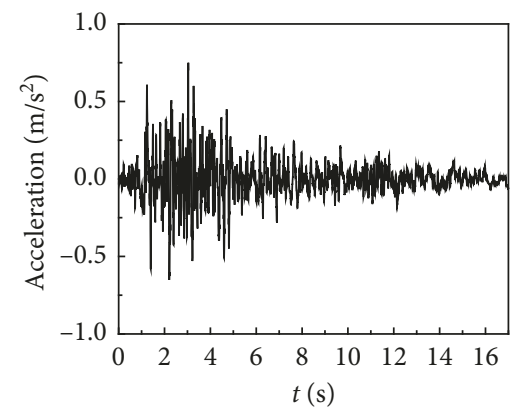

(b)

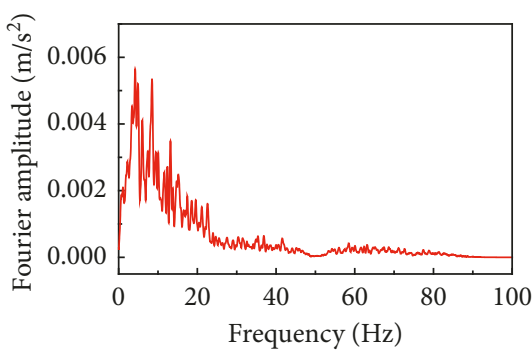

(e)

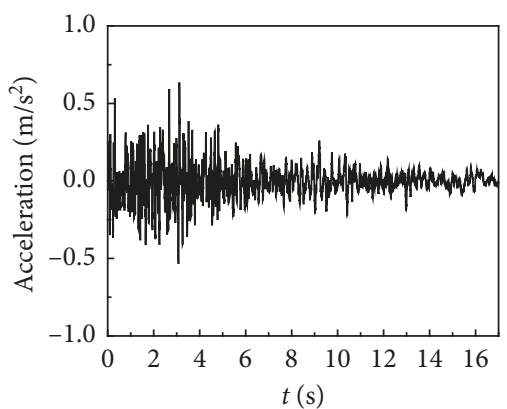

(c)

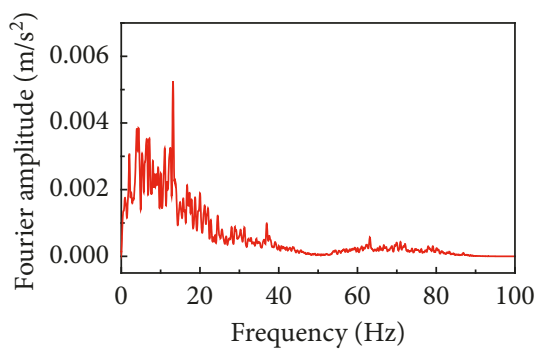

(f)

FIgURE 5: Details of the Taft seismic motion. (a) Time history curve in $x$ direction; (b) time history curve in $y$ direction; (c) time history curve in $z$ direction; (d) Fourier spectra in $x$ direction; (e) Fourier spectra in $y$ direction; (f) Fourier spectra in $z$ direction.

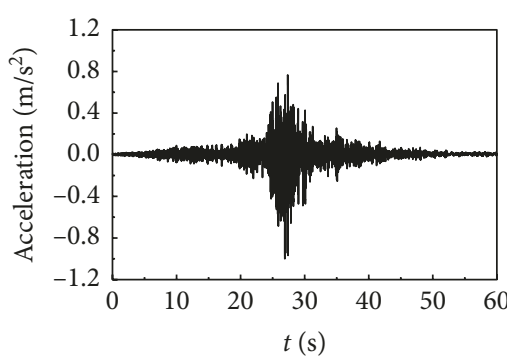

(a)

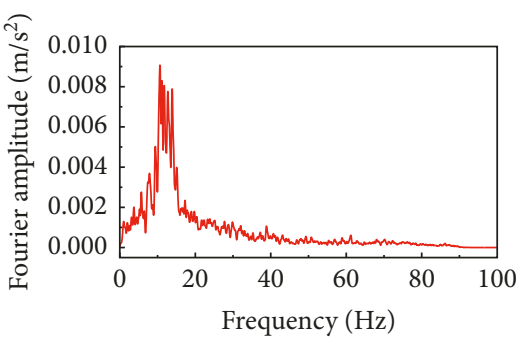

(d)

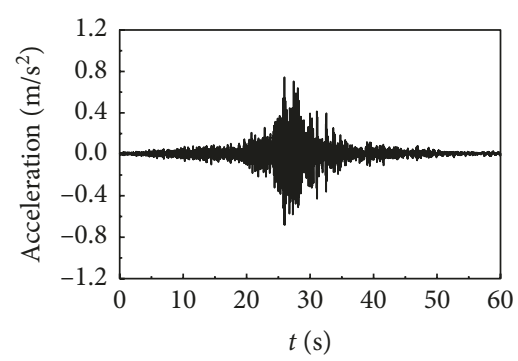

(b)

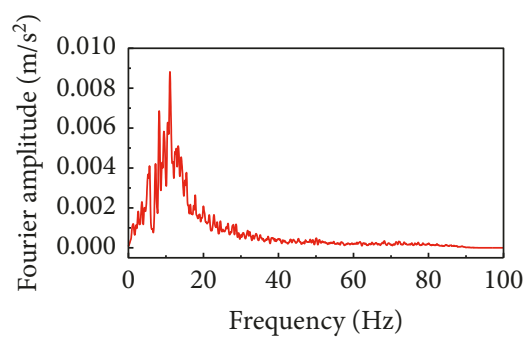

(e)

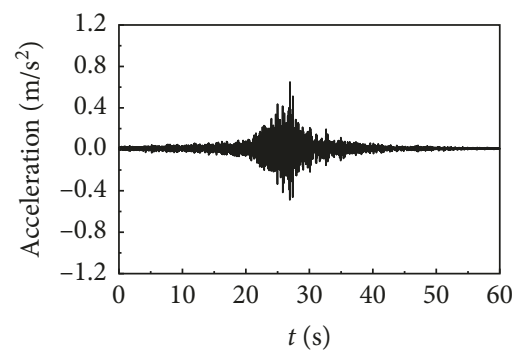

(c)

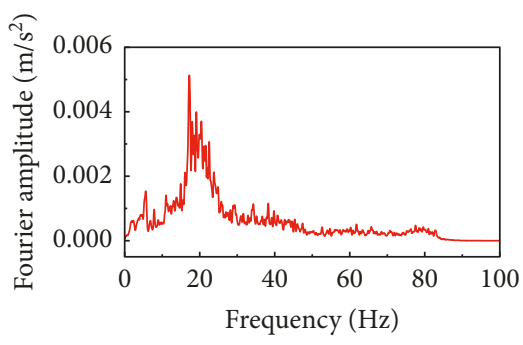

(f)

Figure 6: Details of the 311 seismic motion. (a) Time history curve in $x$ direction; (b) time history curve in $y$ direction; (c) time history curve in $z$ direction; (d) Fourier spectra in $x$ direction; (e) Fourier spectra in $y$ direction; (f) Fourier spectra in $z$ direction. 


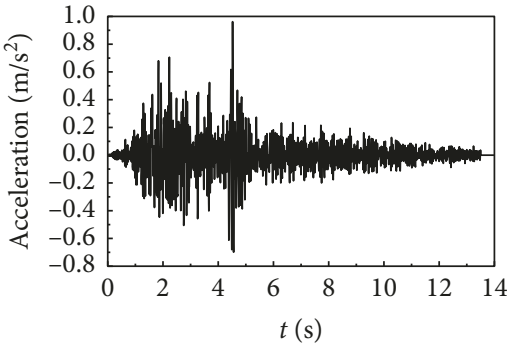

(a)

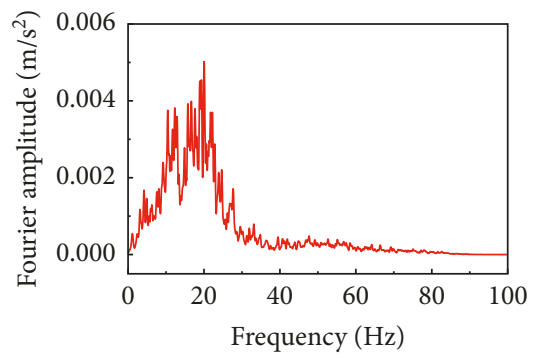

(d)

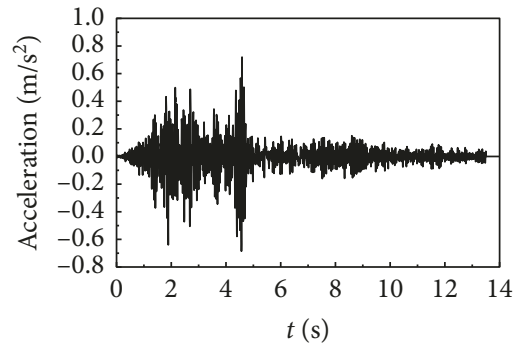

(b)

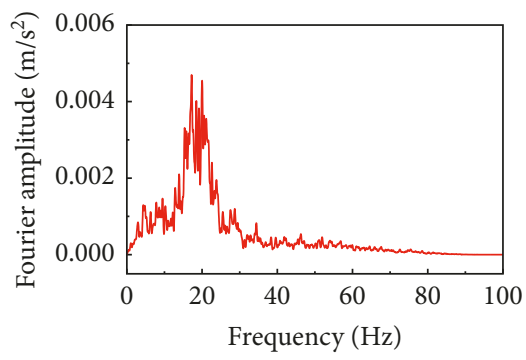

(e)

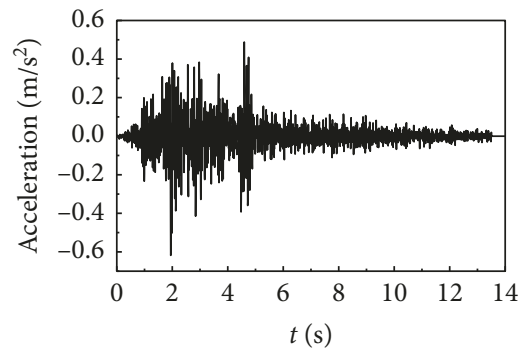

(c)

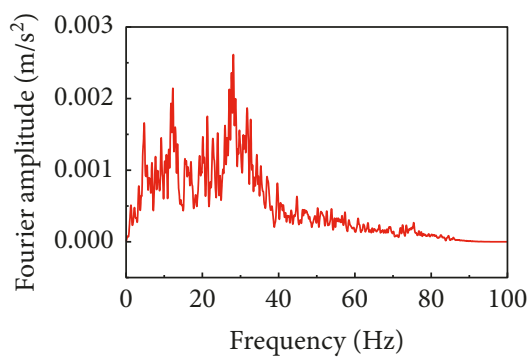

(f)

Figure 7: Details of the Lsfx seismic motion. (a) Time history curve in $x$ direction; (b) time history curve in $y$ direction; (c) time history curve in $z$ direction; (d) Fourier spectra in $x$ direction; (e) Fourier spectra in $y$ direction; (f) Fourier spectra in $z$ direction.

TABLe 7: Details of the Fourier amplitude of the three seismic motions before the application of the isolated supports.

\begin{tabular}{|c|c|c|c|c|c|c|}
\hline $\begin{array}{l}\text { Seismic } \\
\text { motion }\end{array}$ & $\begin{array}{c}\text { Main frequency } \\
\text { range in } x \text { direction }(\mathrm{Hz})\end{array}$ & $\begin{array}{l}\text { The frequency of } \\
\text { peak value }(\mathrm{Hz})\end{array}$ & $\begin{array}{l}\text { Main frequency } \\
\text { range in } y \\
\text { direction }(\mathrm{Hz}) \\
\end{array}$ & $\begin{array}{l}\text { The frequency of } \\
\text { peak value }(\mathrm{Hz})\end{array}$ & $\begin{array}{c}\text { Main frequency } \\
\text { range in } z \text { direction }(\mathrm{Hz})\end{array}$ & $\begin{array}{l}\text { The frequency of } \\
\text { peak value }(\mathrm{Hz})\end{array}$ \\
\hline Taft & $2-10$ & 6.87 & $4-13$ & 4.18 & $2-14$ & 13.15 \\
\hline 311 & $10-15$ & 10.67 & 5-12 & 11.08 & $16-23$ & 17.25 \\
\hline Lsfx & $8-25$ & 20.03 & $15-22$ & 17.22 & $4-33$ & 28.12 \\
\hline
\end{tabular}

with an amplitude of $620 \mathrm{~cm} / \mathrm{s}^{2}$. At the same time, among the 9 measuring points, 6 groups of measuring points reached plastic development. Therefore, the results from the test indicated that the isolated supports considerably reduced the responses of acceleration and stress and are also beneficial, but with a moderate impact on the displacement responses.

5.3. Analysis of Vibration Isolation Efficiency. The isolation rate defined by the ratio of the maximum responses between the structure with the isolated support and the corresponding structure without the isolated support is shown in Equations (3)-(5).

$$
\begin{aligned}
& \operatorname{Ira}=\frac{r_{1}}{r_{2}}, \\
& \operatorname{Ird}=\frac{r_{3}}{r_{4}}, \\
& \text { Irs }=\frac{r_{5}}{r_{6}},
\end{aligned}
$$

where Ira, Ird, and Irs are defined as isolation rate of the acceleration, displacement, and stress; $r_{1}, r_{3}$, and $r_{5}$ are the maximum acceleration, displacement, and stress of the structure with the isolated support; and $r_{2}, r_{4}$, and $r_{6}$ are the corresponding maximum acceleration, displacement, and stress of the structure without the isolated support.

Figures 12(a)-12(i) show the isolation rate of acceleration at the measuring points of A3, A4, and A5 subjected to the three seismic motions as descried from Figures 5-7. The value of isolation rate ranges from 0.013 to 0.304 although the isolation rate varied with different measuring points and seismic ground motions, which indicates that the isolated supports have a promising isolation efficiency. Figures 12(a)-12(c) show the isolation rate of acceleration at the measuring points subjected to Taft seismic motion. The isolated support has a better isolation rate under the seismic motion with the amplitude ranges from $100 \mathrm{~cm} / \mathrm{s}^{2}$ to $620 \mathrm{~cm} / \mathrm{s}^{2}$.

Figures 13(a)-13(i) show the isolation rate of displacement at the measuring points of D3 and D4 subjected to the three seismic motions as descried from Figures 5-7. The value of the isolated rate ranges from 0.184 to 1.84 , which has a similar variation tendency to that of acceleration. Results in Figures 5-7 show that the node displacement at some measuring points was amplified since the isolated supports belonged to the vibration isolation device and did not have a positive isolation effect on the displacement. Figures 13(a)-13(c) show the isolation rate 


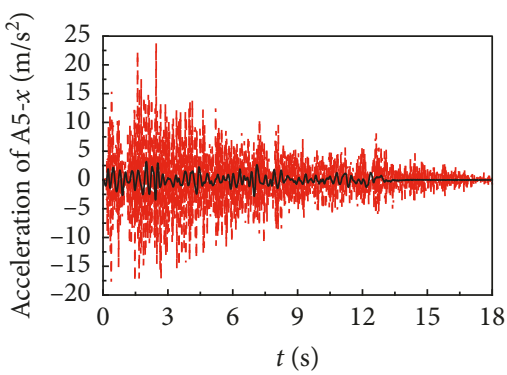

- - - Without isolator

— With isolator

(a)

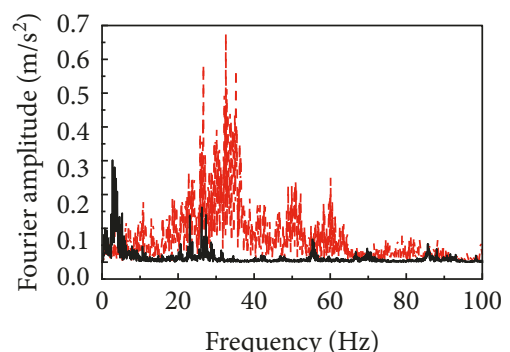

- - - Without isolator

With isolator

(d)

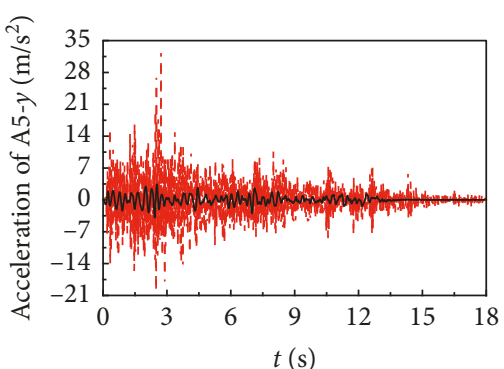

- - - Without isolator

— With isolator

(b)

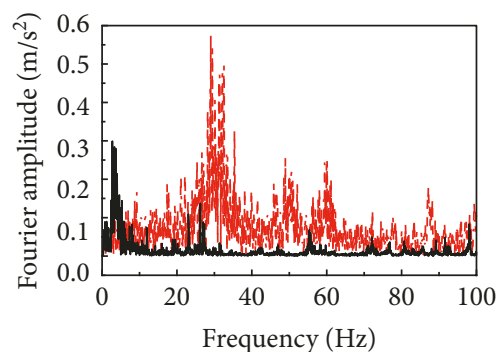

- - Without isolator

— With isolator

(e)

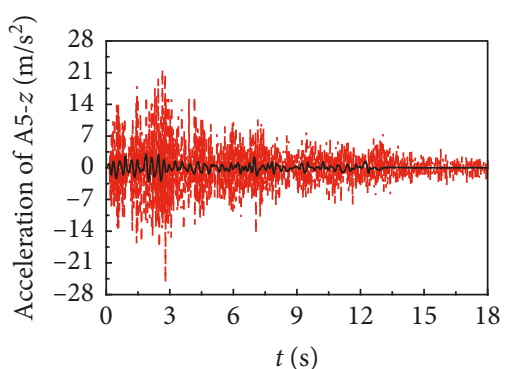

- Without isolator

- With isolator

(c)

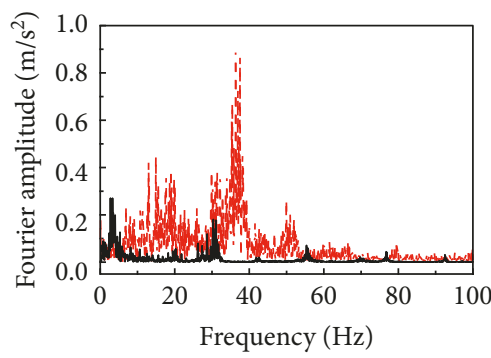

- Without isolator

With isolator

FIGURE 8: Response of acceleration time history and its corresponding Fourier curve of A5 at top node. (a) Response of acceleration of A5- $x$; (b) response of acceleration of A5- $y$; (c) response of acceleration of A5- $z$; (d) Fourier curve of A5- $x$; (e) Fourier curve of A5- $y$; (f) Fourier curve of A5- $z$.

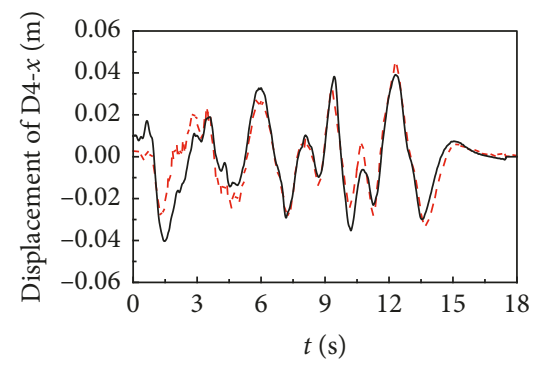

- - - Without isolator

With isolator

(a)

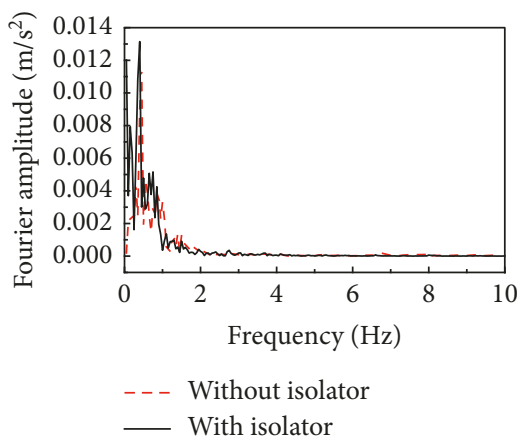

(d)

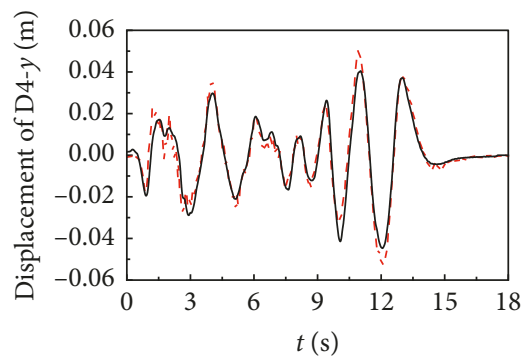

- - - Without isolator

— With isolator

(b)

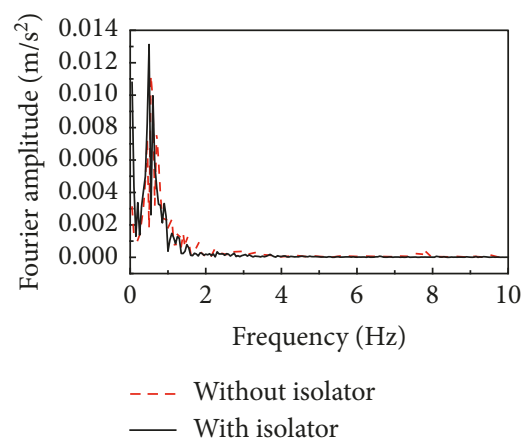

(e)

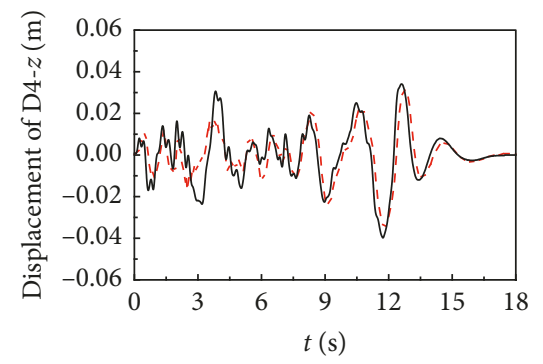

- - - Without isolator With isolator

(c)

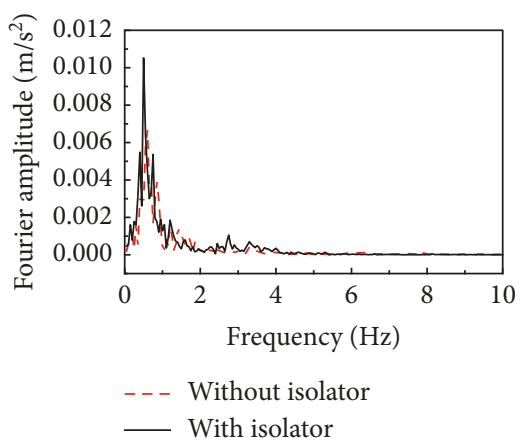

(f)

FIGURE 9: Response of displacement time history and its corresponding Fourier curve of D4 at top node. (a) Response of displacement of D4$x$; (b) response of displacement of D4- $y$; (c) response of displacement of D4- $z$; (d) Fourier curve of D4- $x$; (e) Fourier curve of D4- $y$; (f) Fourier curve of D4- $z$. 


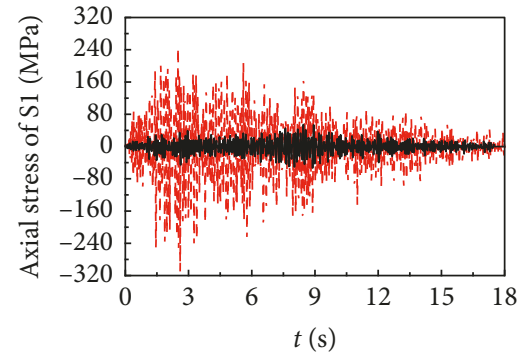

- - Without isolator

_ With isolator

(a)

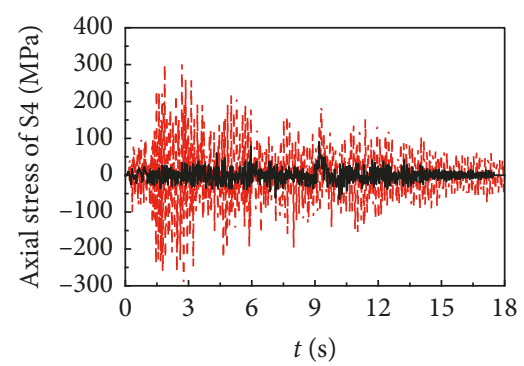

- - - Without isolator

— With isolator

(d)

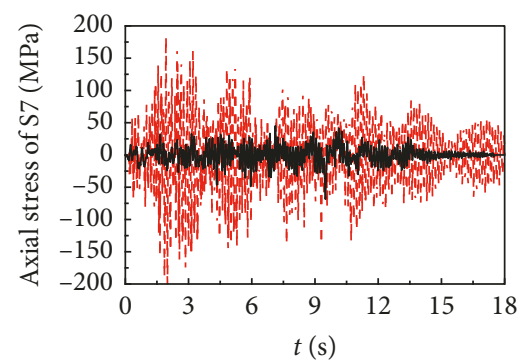

- - Without isolator

— With isolator

(g)

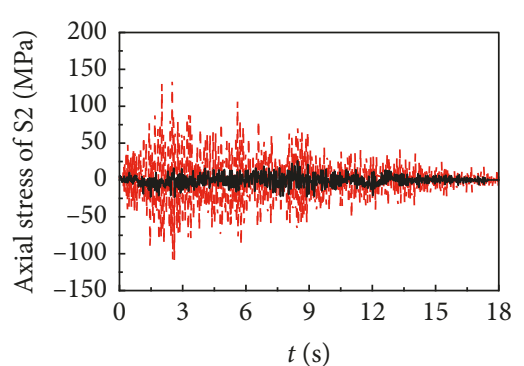

-. - Without isolator

_ With isolator

(b)

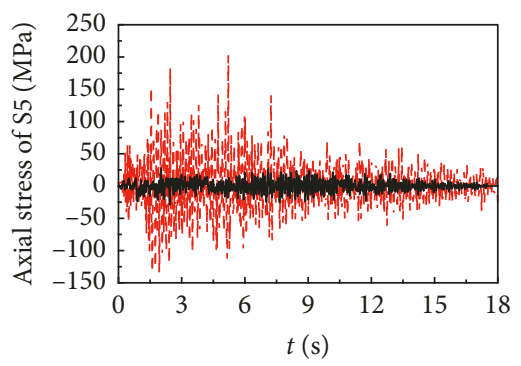

- - - Without isolator

— With isolator

(e)

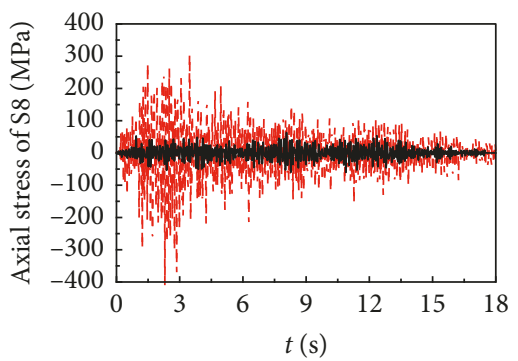

- - - Without isolator

— With isolator

(h)

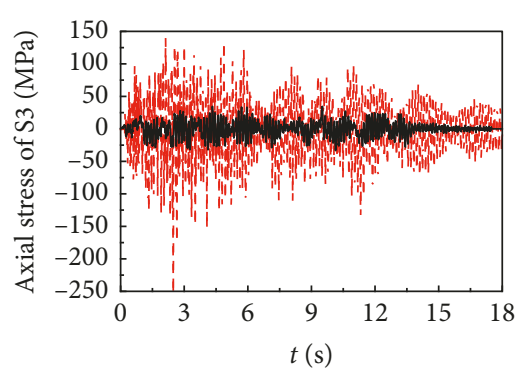

- - - Without isolator

_ With isolator

(c)

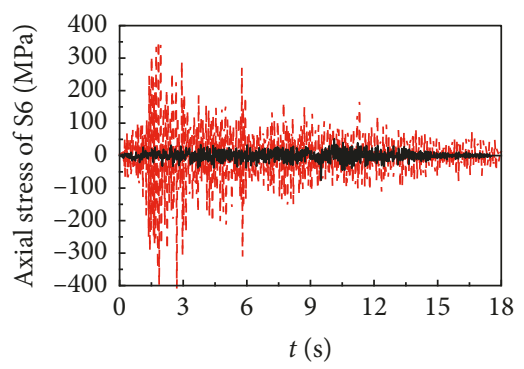

- - Without isolator

— With isolator

(f)

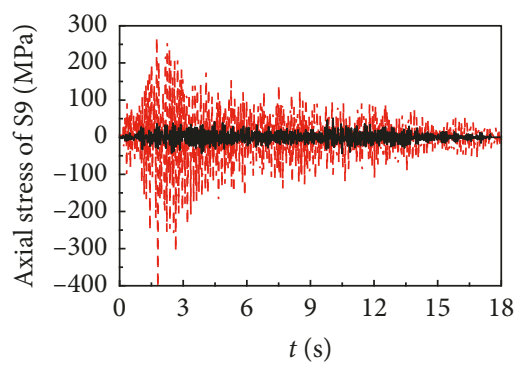

- - - Without isolator

_ With isolator

(i)

Figure 10: Response of stress time history. (a) Response of stress time history of S1; (b) response of stress time history of S2; (c) response of stress time history of S3; (d) response of stress time history of S4; (e) response of stress time history of S5; (f) response of stress time history of S6; (g) response of stress time history of S7; (h) response of stress time history of S8; (i) response of stress time history of S9.

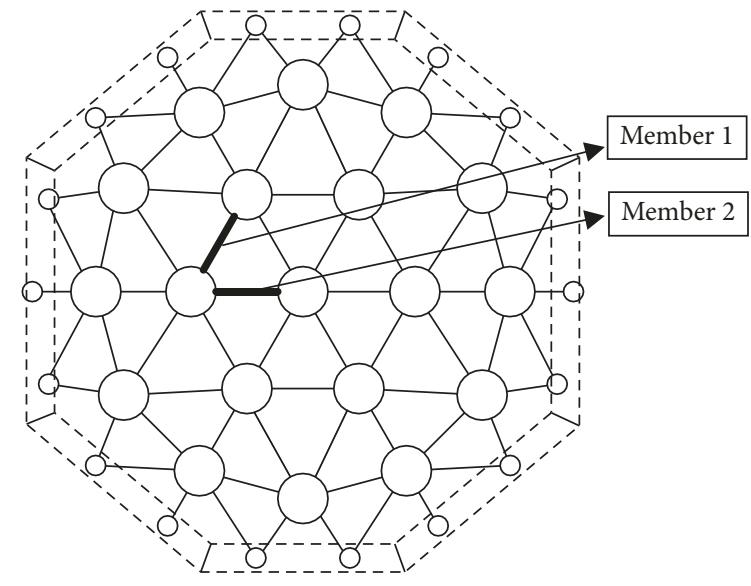

(a)

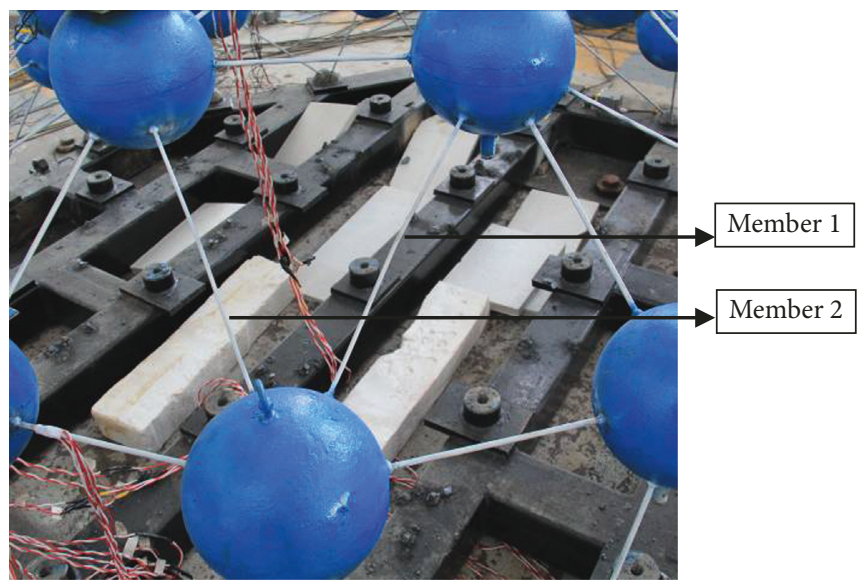

(b)

FIGURE 11: The damaged members in the structure without isolated support under Taft motion with amplitude of $700 \mathrm{~cm} / \mathrm{s}^{2}$. (a) The position of the damage members; (b) damage members in the tested structure. 


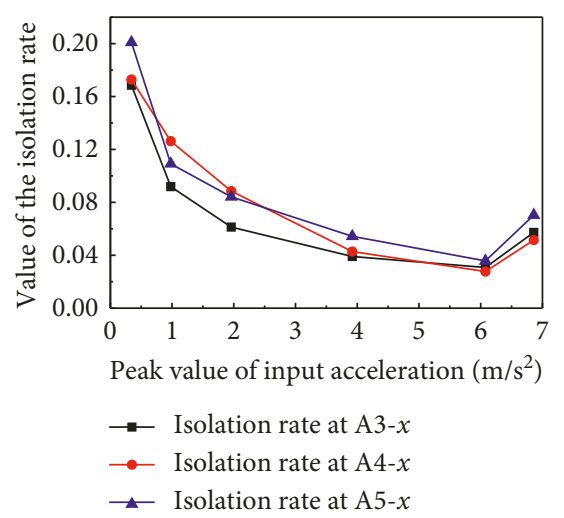

(a)

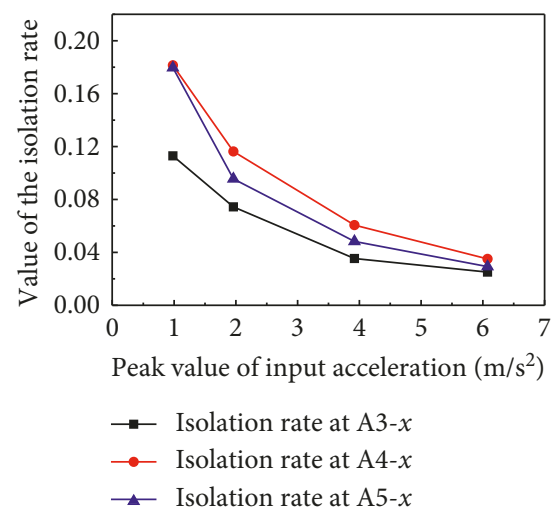

(d)

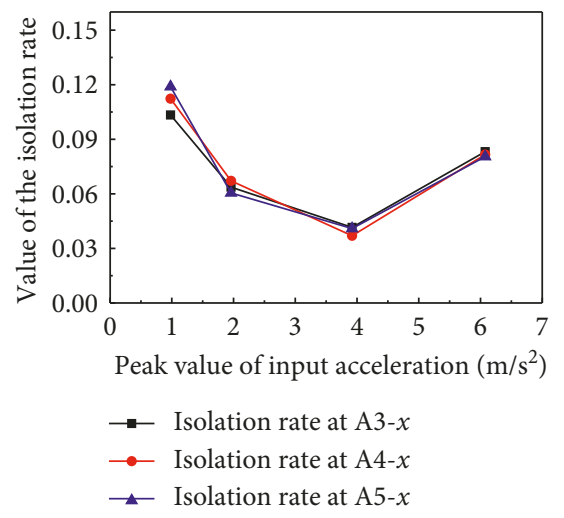

(g)

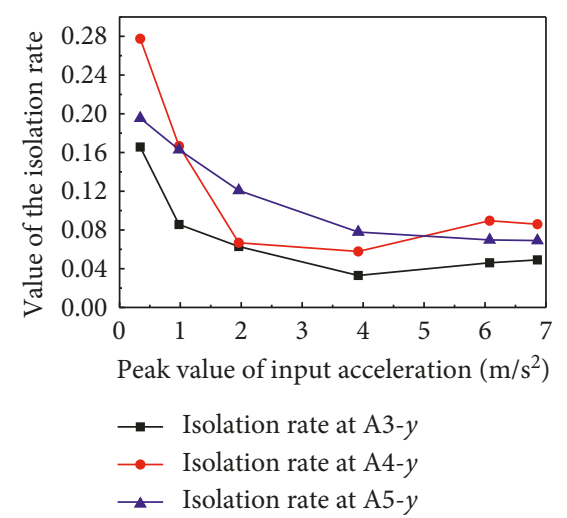

(b)

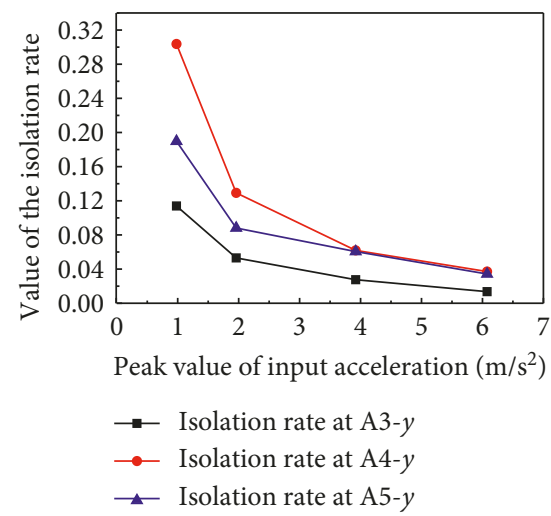

(e)

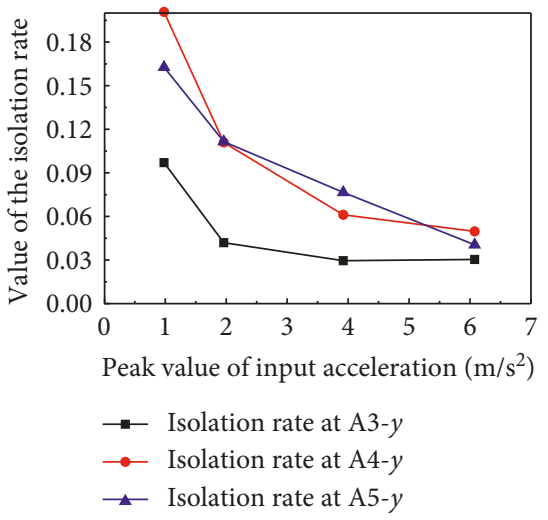

(h)

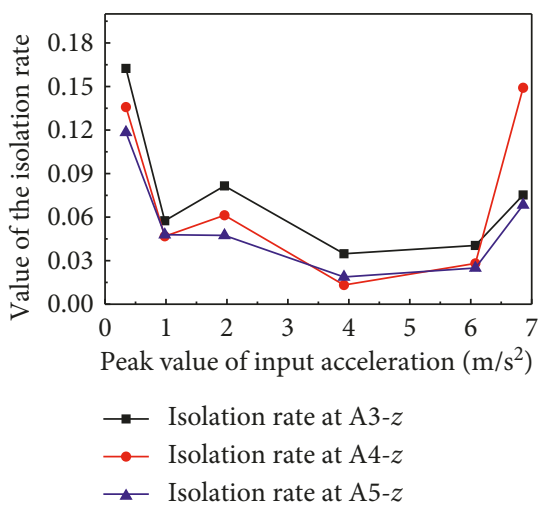

(c)

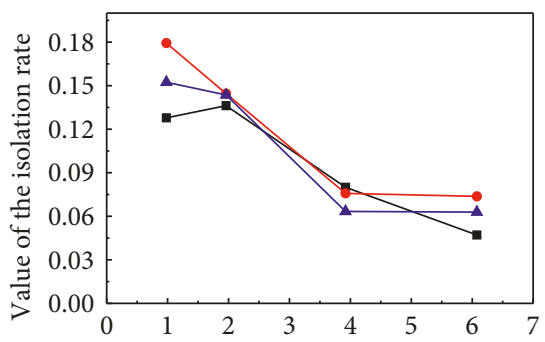

Peak value of input acceleration $\left(\mathrm{m} / \mathrm{s}^{2}\right)$

$\rightarrow$ Isolation rate at $\mathrm{A} 3-z$

$\rightarrow$ Isolation rate at $\mathrm{A} 4-z$

$\rightarrow$ Isolation rate at $\mathrm{A} 5-\mathrm{z}$

(f)

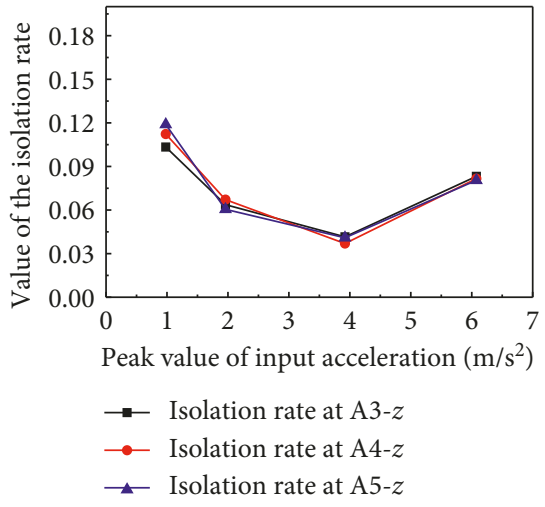

(i)

Figure 12: Vibration isolation rate of acceleration. (a) Under Taft seismic motion in the $x$ direction; (b) under Taft seismic motion in the $y$ direction; (c) under Taft seismic motion in the $z$ direction; (d) under 311 seismic motion in the $x$ direction; (e) under 311 seismic motion in the $y$ direction; (f) under 311 seismic motion in the $z$ direction; (g) under Lsfx seismic motion in the $x$ direction; (h) under Lsfx seismic motion in the $y$ direction; (i) under Lsfx seismic motion in the $z$ direction.

of displacement at the measuring points subjected to Taft seismic motion. The isolated support has a better isolation rate under the seismic motion with amplitude ranging from $100 \mathrm{~cm} / \mathrm{s}^{2}$ to $620 \mathrm{~cm} / \mathrm{s}^{2}$.

Figures 14(a)-14(i) show the isolation rate of stress at 3 measuring points, S2, S6, and S9, subjected to the three seismic motions as descried in Figures 5-7. There were four strain gages in one measuring point symmetrically arrayed along the radial direction of the member. As can be seen from the figures, the isolation rate of stress has a similar variation tendency to that of acceleration. The value of the isolated rate ranges from 0.105 to 0.568 , which indicates that the isolated support has a favorable reduction effect on the stress of the member. Figures 14(d)-14(f) show the isolation rate of displacement at the measuring points subjected to Taft seismic motion, which indicates that the isolated support also has a better isolation rate with the amplitude ranges from $100 \mathrm{~cm} / \mathrm{s}^{2}$ to $620 \mathrm{~cm} / \mathrm{s}^{2}$. 


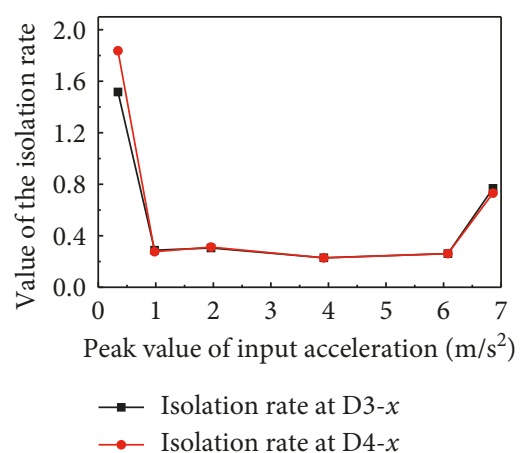

(a)

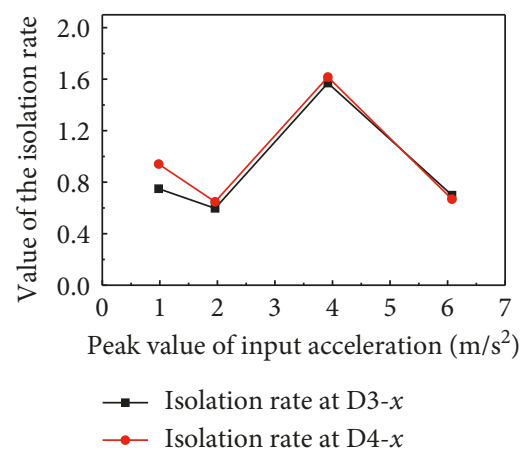

(d)

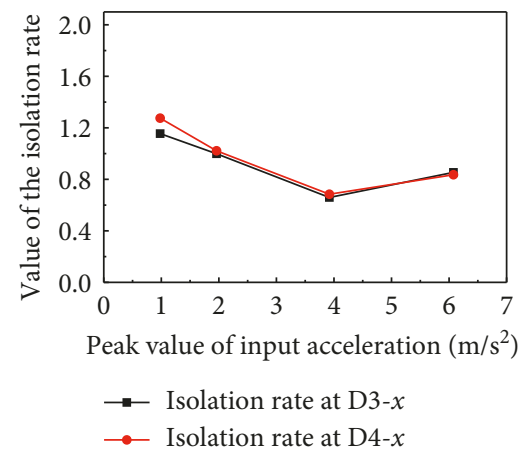

(g)

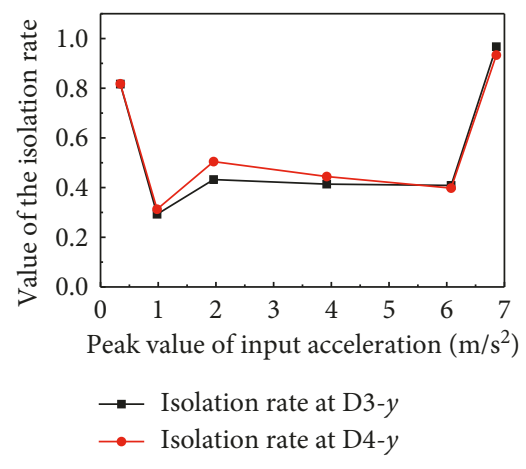

(b)

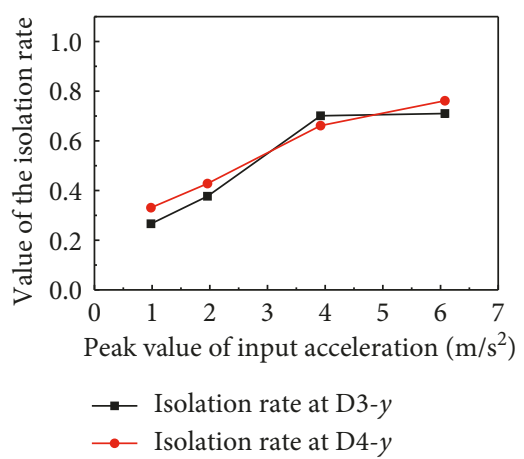

(e)

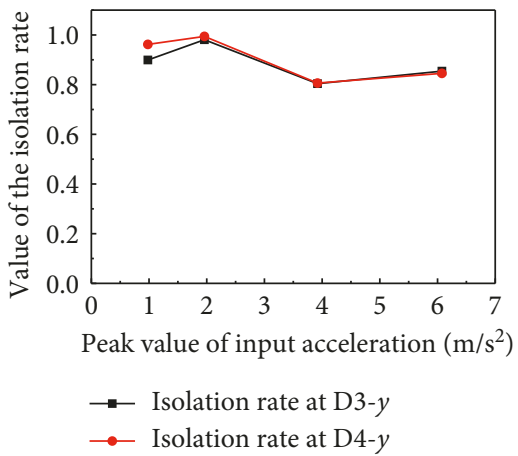

(h)

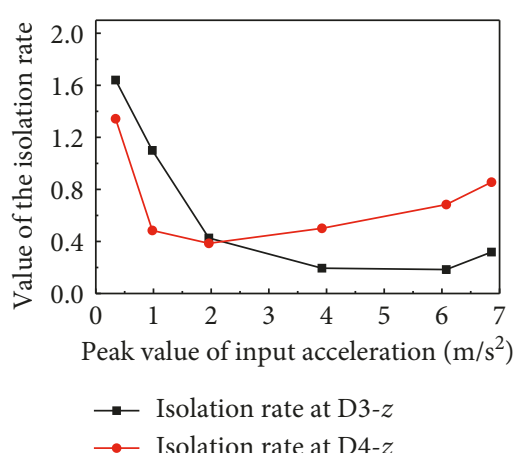

(c)

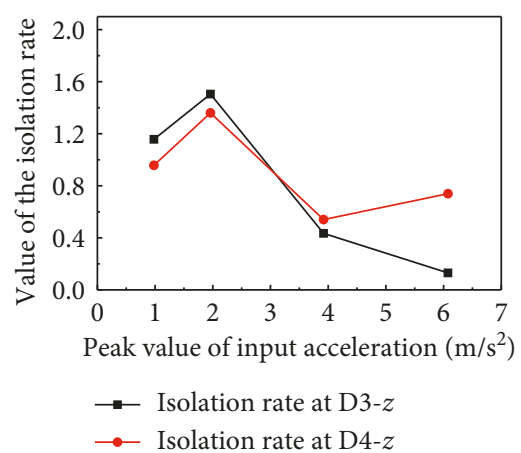

(f)

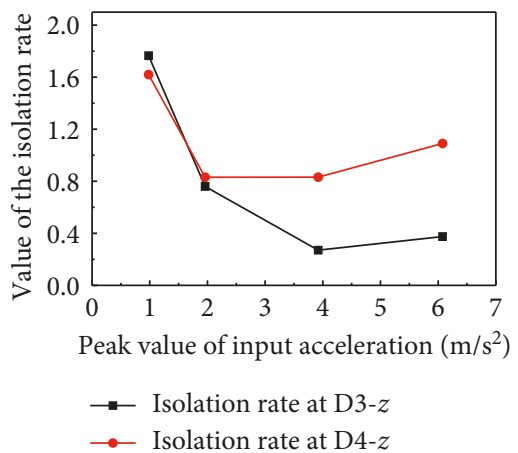

(i)

Figure 13: Vibration isolation rate of displacement. (a) Under Taft seismic motion in the $x$ direction; (b) under Taft seismic motion in the $y$ direction; (c) under Taft seismic motion in the $z$ direction; (d) under 311 seismic motion in the $x$ direction; (e) under 311 seismic motion in the $y$ direction; (f) under 311 seismic motion in the $z$ direction; (g) under Lsfx seismic motion in the $x$ direction; (h) under Lsfx seismic motion in the $y$ direction; (i) under Lsfx seismic motion in the $z$ direction.

\section{Conclusions}

The purpose of this investigation was to study and examine the dynamic behavior of a single-layer reticulated dome before and after application of the isolated support under seismic ground motion. The main drive behind this shaking table test was to investigate the potential for using isolated support in seismic zones. Based on the test results, the following conclusions can be drawn:

(1) A test structure of a single-layer reticulated dome was designed with the corresponding arrangement of measuring points for the acceleration, displacement, and stress. Eight groups of members were then tested using a universal testing machine to obtain the material mechanical properties.

(2) A three-dimensional mechanical isolation device for providing interlayer seismic isolation for large-span space structures with light roof was designed. This device is installed at the top of the column and requires less vertical bearing capacity compared with the traditional base isolation.

(3) Shaking table tests of a single-layer reticulated dome with or without the isolated device were conducted, and it was found that the structure with the isolated support had a promising reduction effect on the acceleration response. The Fourier amplitude with or 


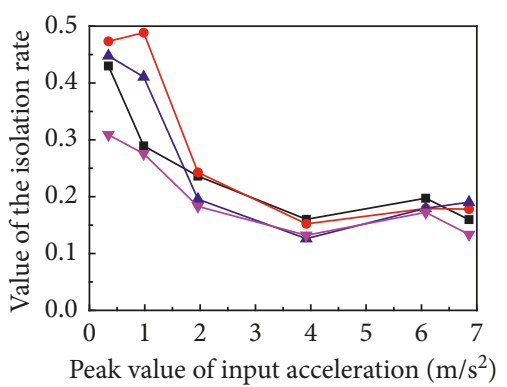

$\rightarrow$ Isolation rate at $\mathrm{S} 21$

- Isolation rate at S22

— Isolation rate at S23

$\rightarrow \quad$ Isolation rate at S24

(a)

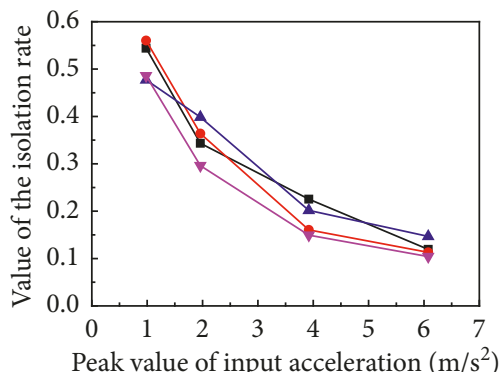

$\rightarrow$ Isolation rate at S21

- Isolation rate at S22

_ Isolation rate at S23

$\longrightarrow$ Isolation rate at S24

(d)

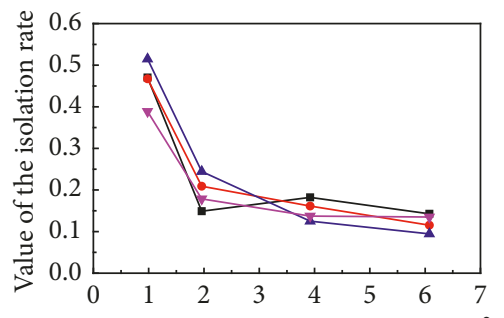

Peak value of input acceleration $\left(\mathrm{m} / \mathrm{s}^{2}\right)$

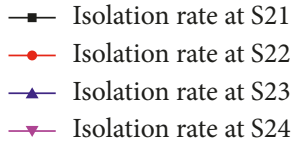

(g)

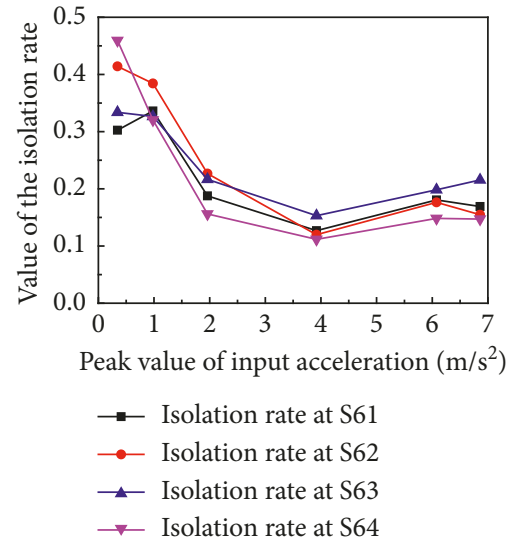

(b)

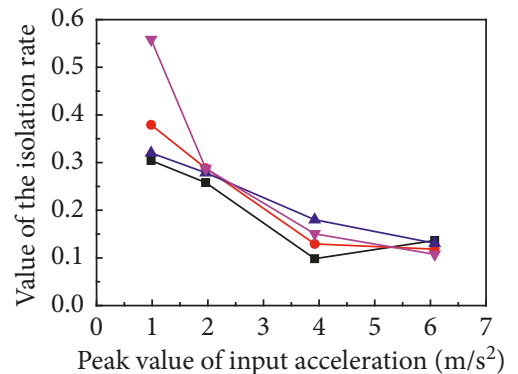

$\rightarrow$ Isolation rate at $\mathrm{S} 61$

$\longrightarrow$ Isolation rate at $\mathrm{S} 62$

— Isolation rate at S63

$\longrightarrow$ Isolation rate at $\mathrm{S} 64$

(e)

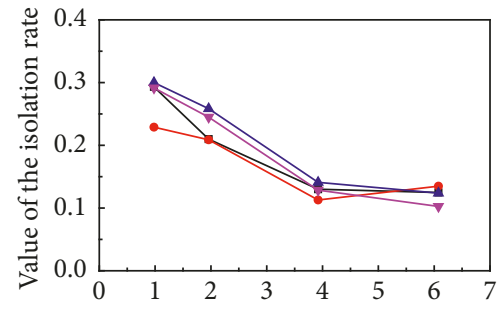

Peak value of input acceleration $\left(\mathrm{m} / \mathrm{s}^{2}\right)$

- Isolation rate at S61

$\longrightarrow$ Isolation rate at $\mathrm{S} 62$

$\_$Isolation rate at $\mathrm{S} 63$

$\rightarrow$ Isolation rate at $\mathrm{S} 64$

(h)

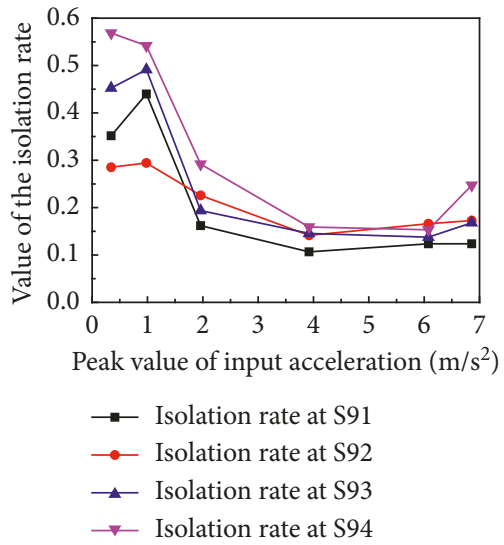

(c)

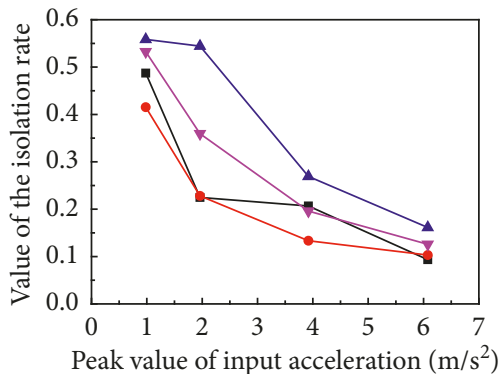

$\longrightarrow$ - Isolation rate at $\$ 91$

$\longrightarrow$ Isolation rate at $\mathrm{S} 92$

— Isolation rate at $\mathrm{S} 93$

$\longrightarrow$ Isolation rate at $\mathrm{S94}$

(f)

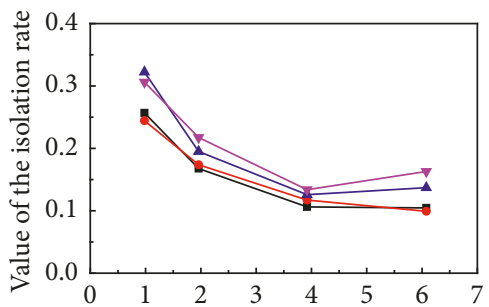

Peak value of input acceleration $\left(\mathrm{m} / \mathrm{s}^{2}\right)$

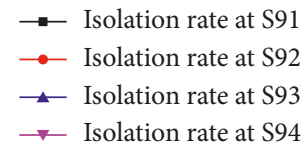

(i)

Figure 14: Vibration isolation rate of stress. (a) S2 under Taft seismic motion; (b) S6 under Taft seismic motion; (c) S9 under Taft seismic motion; (d) S2 under 311 seismic motion; (e) S6 under 311 seismic motion; (f) S9 under 311 seismic motion; (g) S2 under Lsfx seismic motion; (h) S6 under Lsfx seismic motion; (i) S9 under Lsfx seismic motion.

without the isolated supports indicated that the frequencies were significantly changed after application of the isolated supports.

(4) Test results showed that the node displacement at some measuring points was amplified since the isolated supports belong to vibration isolation device and do not have a positive isolation effect on the displacement. Moreover, the isolated support had a better isolation rate under seismic motion with amplitude ranges from $100 \mathrm{~cm} / \mathrm{s}^{2}$ to $620 \mathrm{~cm} / \mathrm{s}^{2}$.

(5) The isolation rate of stress had a similar variation tendency to that of acceleration, and test results indicated that the isolated support had a favorable reduction effect on the stress of the member. Therefore, the isolated support designed in this paper is applicable for large-span space structure with light roof mass. 


\section{Data Availability}

The data used to support the findings of this study are available from the corresponding author upon request.

\section{Conflicts of Interest}

The authors declare that they have no conflicts of interest.

\section{Acknowledgments}

This study is jointly sponsored by China Earthquake Administration Fundamental Research Program (2018B12 and 1520470000001630080301) and National Natural Science Foundation of Heilongjiang Province, China (E2016071), and the financial grant from the China Postdoctoral Science Foundation (Grant no. 2015M580267) and Program for Innovative Research Team in China Earthquake Administration.

\section{References}

[1] C. X. Zhang, G. B. Nie, J. W. Dai et al., "Experimental studies of the seismic behavior of double-layer lattice space structures I: experimental verification," Engineering Failure Analysis, vol. 64, pp. 85-96, 2016.

[2] M. N. Nader and A. Astaneh-Asl, "Shaking table test of rigid, semirigid, and flexible steel frames," Journal of Structural Engineering, vol. 122, no. 6, pp. 589-596, 1996.

[3] D. G. Lignos, T. Hikino, Y. Matsuoka et al., "Collapse assessment of steel moment frames based on e-defense full-scale shake table collapse tests," Journal of Structural Engineering, vol. 139, no. 1, pp. 120-132, 2013.

[4] G. Vasdravellis, M. Valente, and C. A. Castiglioni, "Dynamic response of composite frames with different shear connection degree," Journal of Constructional Steel Research, vol. 65, no. 10-11, pp. 2050-2061, 2009.

[5] L. R. Barroso and R. Rodriguez, "Damage detection utilizing the damage index method to a benchmark structure," Journal of Engineering Mechanics, vol. 130, no. 2, pp. 142-151, 2004.

[6] X. M. Zhou and G. Q. Li, "A macro-element based practical structure for seismic analysis of steel-concrete composite high-rise buildings," Engineering Structures, vol. 49, pp. 91103, 2013.

[7] M. Schachter and A. M. Reinhorn, "Dynamic analysis of three-dimensional frames with material and geometric nonlinearities," Journal of Structural Engineering, vol. 137, no. 2, pp. 207-219, 2011.

[8] J. E. Rodgers and S. A. Mahin, "Effects of connection fractures on global behavior of steel moment frames subjected to earthquakes," Journal of Structural Engineering, vol. 132, no. 1, pp. 78-88, 2006.

[9] M. Domizio, D. Ambrosini, and O. Curadelli, "Experimental and numerical analysis to collapse of a framed structure subjected to seismic loading," Engineering Structures, vol. 82, pp. 22-32, 2015.

[10] C. S. Huang, S. L. Hung, C. I. Lin et al., "A wavelet-based approach to identifying structural modal parameters from seismic response and free vibration data," Computer-Aided Civil and Infrastructure Engineering, vol. 20, no. 6, pp. 408423, 2005.

[11] Y. J. Yu, K. C. Tsai, Y. T. Weng et al., "Analytical studies of a full-scale steel building shaken to collapse," Engineering Structures, vol. 32, no. 10, pp. 3418-3430, 2010.
[12] R. Vargas and M. Bruneau, "Experimental response of buildings designed with metallic structural fuses. II," Journal of Structural Engineering, vol. 135, no. 4, pp. 394-403, 2009.

[13] T. K. Lin, K. C. Chang, L. L. Chung et al., "Active control with optical fiber sensors and neural networks. I: theoretical analysis," Journal of Structural Engineering, vol. 132, no. 8, pp. 1293-1303, 2006.

[14] T. K. Lin, K. C. Chang, and Y. B. Lin, "Active control with optical fiber sensors and neural networks. II: experimental verification," Journal of Structural Engineering, vol. 132, no. 8, pp. 1304-1313, 2006.

[15] F. F. Sun, G. Q. Li, X. K. Guo et al., "Development of new-type buckling-restrained braces and their application in a seismic steel frameworks," Advances in Structural Engineering, vol. 14, no. 4, pp. 717-730, 2011.

[16] S. Yan, J. Niu, P. Mao et al., "Experimental research on passive control of steel frame structure using SMA wires," Mathematical Problems in Engineering, vol. 2013, Article ID 416282, 12 pages, 2013.

[17] H. S. Monir and K. Zeynali, "A modified friction damper for diagonal bracing of structures," Journal of Constructional Steel Research, vol. 87, no. 6, pp. 17-30, 2013.

[18] J. S. Hwang, Y. N. Huang, and Y. H. Hung, "Analytical and experimental study of toggle-brace-damper systems," Journal of Structural Engineering, vol. 131, no. 7, pp. 1035-1043, 2005.

[19] K. C. Chang, T. T. Soong, S. T. Oh et al., "Seismic behavior of steel frame with added viscoelastic dampers," Journal of Structural Engineering, vol. 121, no. 10, pp. 1418-1426, 1995.

[20] N. Wongprasert and M. D. Symans, "Experimental evaluation of adaptive elastomeric base-isolated structures using variableorifice fluid dampers," Journal of Structural Engineering, vol. 131, no. 6, pp. 867-877, 2005.

[21] X. D. Zhi, F. Fan, and S. Shen, "Failure mechanisms of singlelayer reticulated domes subjected to earthquakes," Journal of the International Association for Shell and Spatial Structures, vol. 48, no. 1, pp. 29-44, 2007.

[22] G. B. Nie, F. Fan, X. D. Zhi et al., "Shaking table test on failure mechanism of single-layer reticulated dome," China Civil Engineering Journal, vol. 46, no. 10, pp. 17-25, 2013. 


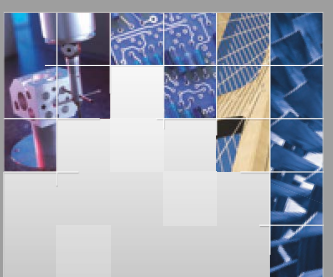

\section{Enfincering}
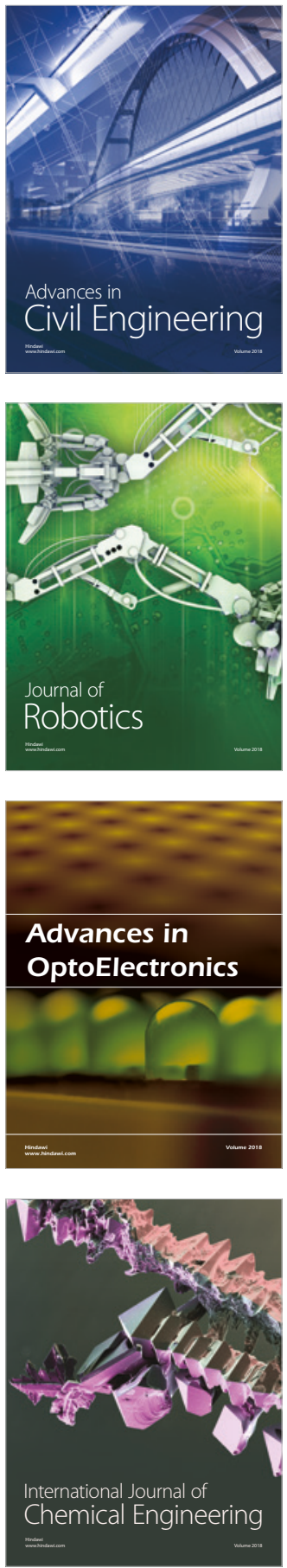

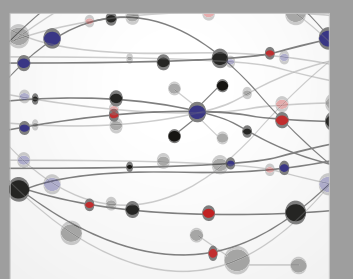

\section{Rotating \\ Machinery}

The Scientific World Journal

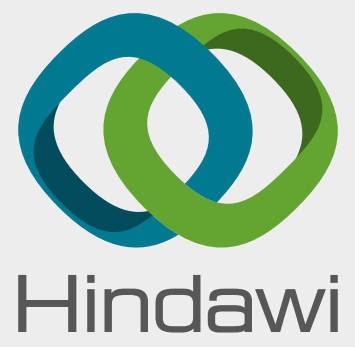

Submit your manuscripts at

www.hindawi.com
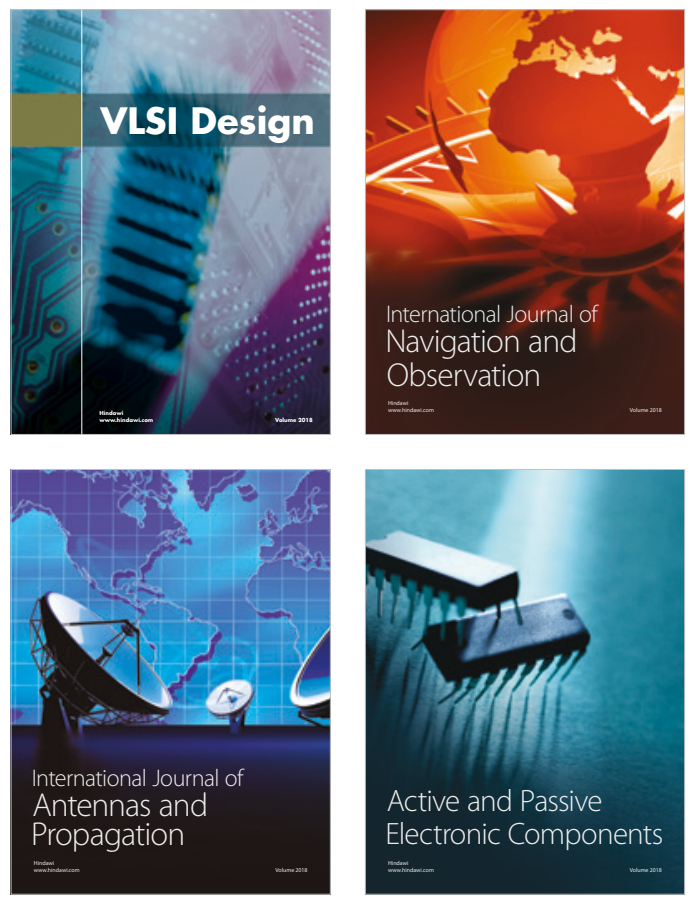
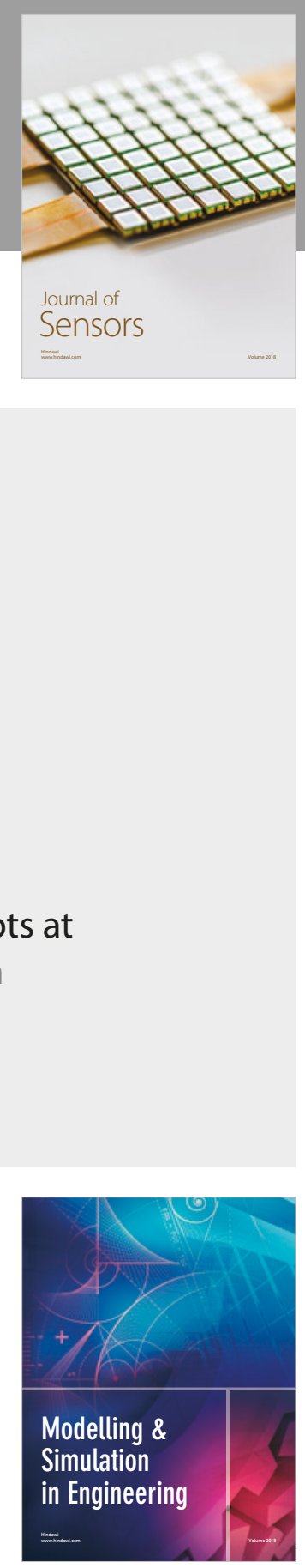

\section{Advances \\ Multimedia}
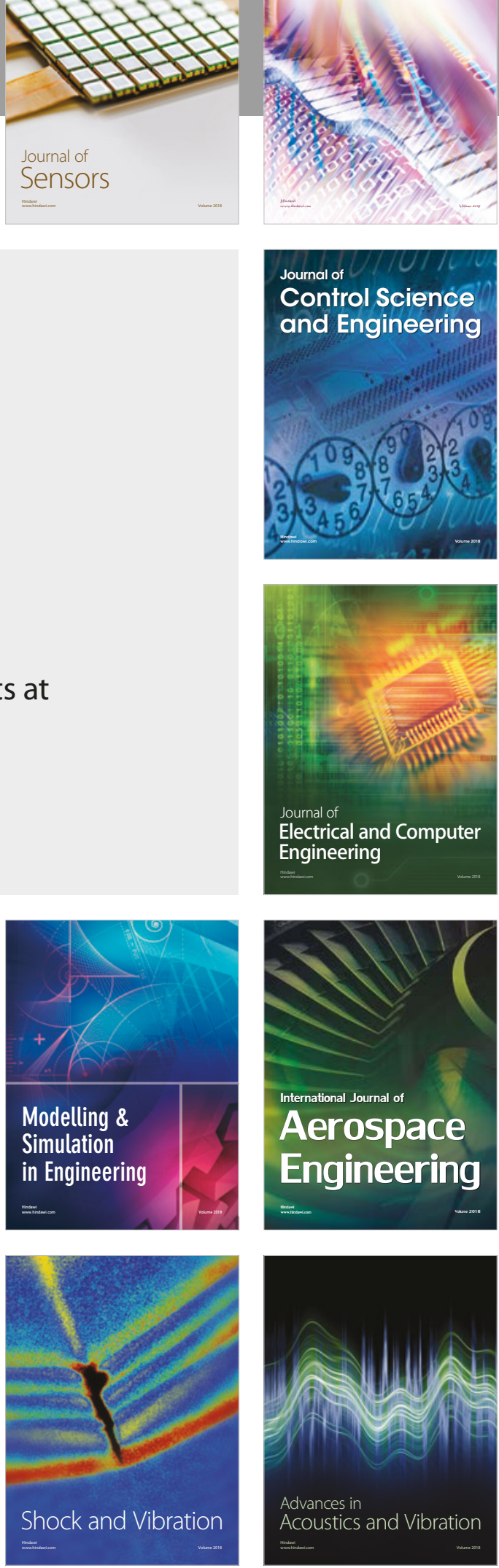